\title{
Relaxin Regulates Myofibroblast Contractility and Protects against Lung Fibrosis
}

\author{
Xiangwei Huang, ${ }^{*}$ Ying Gai, ${ }^{,}$Naiheng Yang, ${ }^{*}$ \\ Baogen Lu, ${ }^{*}$ Chrishan S. Samuel, ${ }^{\dagger}$ \\ Victor J. Thannickal, ${ }^{\star}$ Yong Zhou* \\ From the Division of Pulmonary, Allergy, and Critical Care \\ Medicine, ${ }^{*}$ Department of Medicine, and the Department of \\ Biomedical Engineering,, University of Alabama at Birmingham, \\ Birmingham, Alabama; and the Howard Florey Institute and the \\ Department of Biochemistry and Molecular Biology, ${ }^{\dagger}$ University \\ of Melbourne, Parkville, Australia
}

Myofibroblasts are specialized contractile cells that participate in tissue fibrosis and remodeling, including idiopathic pulmonary fibrosis (IPF). Mechanotransduction, a process by which mechanical stimuli are converted into biochemical signals, regulates myofibroblast differentiation. Relaxin is a peptide hormone that mediates antifibrotic effects through regulation of collagen synthesis and turnover. In this study, we demonstrate enhanced myofibroblast contraction in bleomycin-induced lung fibrosis in mice and in fibroblastic foci of human subjects with IPF, using phosphorylation of the regulatory myosin light chain $\left(\mathrm{MLC}_{20}\right)$ as a biomarker of in vivo cellular contractility. Compared with wild-type mice, relaxin knockout mice express higher lung levels of phospho-MLC 20 and develop more severe bleomycin-induced lung fibrosis. Exogenous relaxin inhibits $\mathrm{MLC}_{20}$ phosphorylation and bleomycin-induced lung fibrosis in both relaxin knockout and wild-type mice. Ex vivo studies of IPF lung myofibroblasts demonstrate decreases in $\mathrm{MLC}_{20}$ phosphorylation and reduced contractility in response to relaxin. Characterization of the signaling pathway reveals that relaxin regulates $\mathrm{MLC}_{20}$ dephosphorylation and lung myofibroblast contraction by inactivating RhoA/Rho-associated protein kinase through a nitric oxide/cGMP/protein kinase G-dependent mechanism. These studies identify a novel antifibrotic role of relaxin involving the inhibition of the contractile phenotype of lung myofibroblasts and suggest that targeting myofibroblast contractility with relaxin-like peptides may be of therapeutic benefit in the treatment of fibrotic lung disease. (Am J Pathol 2011, 179:2751-2765; DOI: 10.1016/j.ajpath.2011.08.018)
Idiopathic pulmonary fibrosis (IPF) is a lethal fibrotic lung disease characterized by excessive deposition of extracellular matrix (ECM) in the lung parenchyma. Myofibroblasts are key effectors of the tissue remodeling process in IPF. ${ }^{1}$ These cells are specialized contractile cells that possess characteristics of both ECM-producing fibroblasts and $\alpha$-smooth muscle actin ( $\alpha$-SMA)-expressing smooth muscle cells (SMCs). ${ }^{2}$ Recent studies ${ }^{3-6}$ suggest that acquisition of contractile activity may not simply be a phenotypic marker of myofibroblasts; rather, myofibroblast contractile force generation may provide a feedforward mechanism for maintaining persistent myofibroblast differentiation in progressive fibrosis through the conversion of mechanical stimuli into biochemical signals, a process known as mechanotransduction. ${ }^{7}$ Understanding the (dys)regulation of myofibroblast contraction will provide necessary means for the determination of the role of myofibroblast contraction in the regulation of persistent/progressive fibrosis and may potentially lead to effective therapeutic approaches for the treatment of devastating fibrotic diseases.

Recent evidence ${ }^{5}$ supports the concept that myofibroblast mechanotransduction involves fibrogenic signaling via contractile force-mediated activation of latent transforming growth factor (TGF)- $\beta 1$ bound to the ECM. In this process, stress fiber-generated contractility is transmitted from the cytoskeleton to the ECM through the transmembrane integrins, primarily integrin $\alpha_{\mathrm{v}} \beta_{5}{ }^{5}$ The force transmission causes a conformational change of the ECM-bound latent TGF- $\beta 1$ complex, leading to the release (or exposure) of active TGF- $\beta 1$ that is then able to bind to its cognate receptor(s). Recent studies ${ }^{6}$ from our laboratory demonstrated that interruption of integrin $\alpha_{\mathrm{v}} \beta_{5}$-TGF- $\beta 1$ interactions by Thy- 1 , a glycosyl-phospha-

Supported by NIH grant HL097215 and American Heart Association Scientist Development Grant 0835432N (Y.Z.); NIH grants HL067967 and HL107181 (V.J.T.); National Heart Foundation of Australia and National Health \& Medical Research Council of Australia R.D. Wright Fellowship (C.S.S.).

Accepted for publication August 22, 2011.

Address reprint requests to Yong Zhou, Ph.D., Division of Pulmonary, Allergy and Critical Care Medicine, Department of Medicine, Tinsley Harrison Tower 437B, 1900 University Blvd, Birmingham, AL 35294. E-mail: yzhou@uab.edu. 
tidylinositol-linked cell surface protein, blocks fibroblast contraction-induced latent TGF- $\beta 1$ activation and TGF$\beta 1-$ dependent lung myofibroblast differentiation. In addition to this extrinsic pathway, myofibroblast contraction may trigger fibrogenic mechanotransduction via an intrinsic pathway that involves the release/activation of intracellular transcription factor(s). Contractile force generation is primarily regulated by Rho/Rho-associated kinase (ROCK) signaling, which regulates actin cytoskeleton dynamics. ${ }^{8-11}$ Activation of Rho/ROCK promotes monomeric G-actin polymerization into filamentous actin (Factin), resulting in nuclear import of myocardin-related transcription factor-A, a serum-responsive factor coactivator. ${ }^{12}$ In the nucleus, myocardin-related transcription factor-A binds serum-responsive factor and activates fibrogenic gene programs that promote myofibroblast differentiation, collagen synthesis, and myofibroblast survival. ${ }^{13-16}$ In addition, cell-derived contractile forces unfold the cryptic sites of ECM protein fibrils, which may potentially trigger autofibrillogenesis and long matrix fibril formation. ${ }^{17}$ Similarly, fibroblast contraction-induced mechanical deformation renders an extra domain-A fibronectin segment available for specific integrins, a process essential for TGF- $\beta 1$-induced myofibroblast differentiation. ${ }^{18,19}$ In addition to cell-derived contractile forces, externally applied forces (eg, stretching and breathing) and changes in the mechanical properties of the ECM (eg, matrix stiffness) may also activate mechanotransduction events that regulate cellular functions.

Both muscle contraction and nonmuscle cell contraction are regulated by myosin light chain $\left(\mathrm{MLC}_{20}\right)$ phosphorylation. ${ }^{2}$ When phosphorylated, $\mathrm{MLC}_{20}$ triggers actin filaments to slide past one another to power actin cytoskeletal contraction. ${ }^{20}$ Dephosphorylation of $\mathrm{MLC}_{20}$ results in relaxation of the initial and sustained phase of contraction. ${ }^{21,22}$ Mechanisms invoked for sustained myofibroblast contraction involve inhibition of MLC phosphatase activity via activation of the small GTPase RhoA and its downstream target ROCK. On activation, ROCK promotes $\mathrm{MLC}_{20}$ phosphorylation by inhibition of MLC phosphatase via phosphorylation of the regulatory myosin phosphatase targeting subunit-1 (MYPT1) and the MLC phosphatase inhibitors PKC-potentiated phosphatase inhibitor of $17 \mathrm{kDa}$ and phosphatase holoenzyme inhibitor-1. ${ }^{23,24}$

Relaxin is a 6-kDa peptide hormone that is structurally related to the insulin family of peptides ${ }^{25}$ and inhibits fibrogenesis in multiple organs, including the lung. ${ }^{26}$ Continuous infusion of relaxin using s.c. implanted osmotic minipumps reduces alveolar thickening and collagen deposition in bleomycin-treated CBA/J mice and inhibits the accumulation of collagen in the airways of sensitized mice and guinea pigs in response to ovalbumin. ${ }^{27-29}$ Relaxin knockout (KO) mice develop age-associated pulmonary fibrosis, which can be partially reversed by supplementation of exogenous relaxin. ${ }^{30}$ In addition, established fibrosis in aged relaxin $\mathrm{KO}$ mice appears to be further exacerbated by exposure to ovalbumin. ${ }^{31}$ In vitro studies ${ }^{32-38}$ have shown that relaxin inhibits collagen production and increases matrix metalloproteinase expression/activity by cardiac, renal, and skin fibroblasts. Exposure of activated hepatic stellate cells to relaxin results in decreased collagen synthesis and deposition; tissue inhibitors of metalloproteinases 1 and 2 are decreased in the cell-conditioned media. ${ }^{39}$ Based on these findings, the ability to regulate collagen synthesis and turnover may mediate the antifibrotic effect of relaxin. More recent studies ${ }^{40,41}$ report that relaxin inhibits TGF- $\beta 1$-stimulated myofibroblast differentiation, both in cultured renal fibroblasts in vitro and in myocardial infarction-induced cardiac fibrosis in vivo, suggesting that relaxin regulates myofibroblast differentiation in addition to modulating collagen synthesis and turnover.

Relaxin inhibits uterine artery and myometrium contraction in pregnant rats and cervical smooth muscle contraction in women in early pregnancy. ${ }^{42-44}$ In vitro studies $^{45-47}$ showed that relaxin induces relaxation of myometrial cells, vascular SMCs, and TGF- $\beta 1$-treated renal fibroblasts. In the present study, we tested the hypothesis that relaxin inhibits myofibroblast contractility and mediates antifibrotic effects in vivo. We show that relaxin induces dephosphorylation of $\mathrm{MLC}_{20}$ and inhibits contraction of lung myofibroblasts isolated from patients with IPF. Overexpression of phosphomimetic $\mathrm{MLC}_{20}$ mutant blocks relaxin inhibition of lung myofibroblast contraction. Furthermore, our studies indicate that relaxin mediates $\mathrm{MLC}_{20}$ dephosphorylation and lung myofibroblast relaxation by induction of RhoA phosphorylation and ROCK inhibition through a nitric oxide (NO)/cGMP/ protein kinase $\mathrm{G}$ (PKG)-dependent mechanism. In vivo studies show that $M L C_{20}$ phosphorylation is increased in the fibroblastic foci in both human IPF and bleomycintreated mouse lung fibrosis. Mice null for relaxin express higher levels of phospho-MLC $\mathrm{M}_{20}$ and develop more severe lung fibrosis in response to bleomycin compared with wild-type (WT) mice. Continuous infusion of recombinant relaxin for 7 days (days 14 to 21 after bleomycin injury) inhibits bleomycin-induced $\mathrm{MLC}_{20}$ phosphorylation and attenuates lung fibrosis in both $\mathrm{KO}$ and WT mice. Together, this study identifies a novel antifibrotic mechanism of relaxin involving the inhibition of myofibroblast contractility.

\section{Materials and Methods}

\section{Antibodies, Plasmids, and Reagents}

Anti-phospho-MLC ${ }_{20}$ antibody for immunohistochemical (IHC) and immunofluorescent staining and anti-green fluorescent protein antibody were obtained from Rockland Immunochemicals (Gillbertsville, PA). Anti-phospho-MLC 20 antibody and anti-MLC 20 antibody for immunoblot analyses were obtained from Cell Signaling (Danvers, MA). Isoform-specific anti-neuronal NO synthase (nNOS), anti-inducible NO synthase (iNOS), and anti-endothelial NOS (eNOS) antibodies were from Enzo Life Sciences (Plymouth Meeting, PA). Anti-phospho-RhoA (Ser188) was from EMD Chemicals (Gibbstown, $\mathrm{NJ}$ ). Anti-ROK $\alpha / \mathrm{ROCK}$ II antibody was from Millipore (Billerica, MA). Anti-RhoA antibody and anti-glyceraldehyde-3-phosphate dehydrogenase (GAPDH) antibody were from Santa Cruz Biotechnology (Santa Cruz, CA). Anti- $\alpha$-SMA antibody 
was from Sigma (St. Louis, MO). Anti-phospho-moesin (Thr558) antibody and anti-moesin antibody were from Abcam (Cambridge, MA). All secondary antibodies were from Southern Biotech (Birmingham, AL).

Plasmids encoding an N-terminal enhanced GFP tag and human WT MLC 20 or mutated $\mathrm{MLC}_{20}$, in which Thr18 and Ser 19 were replaced with aspartic acids (DD-MLC ${ }_{20}$, a phosphomimetic mutant), were constructed as previously described. ${ }^{48}$ pEGFP-RhoA ${ }^{\mathrm{v} 14}$ plasmid was generated by subcloning a Rho $\mathrm{A}^{\mathrm{V} 14}$ fragment from pcDNA3RhoA ${ }^{\mathrm{V} 14}$ (UMR cDNA Resource Center, Rolla, $\mathrm{MO}$ ) into pEGFPC1 plasmid (Clontech, Mountain View, CA). pEGFP-RhoA ${ }^{\text {v14A188 }}$ was generated using the QuikChange site-directed mutagenesis kit (Stratagene, La Jolla, CA).

Recombinant Human Relaxin 2 was obtained from R\&D Systems (Minneapolis, MN). Pure Silicone Fluid $(30,000$ cSt) was from Clearco (Bensalem, PA). Cyclic AMP Enzyme Immunoassay kit was obtained from Assay Designs (Ann Arbor, MI). Masson's Trichrome Method for Connective Tissue was obtained from Poly Scientific (Bay Shore, NY). PepTag assay for nonradioactive detection of cAMP-dependent protein kinase was from Promega (Madison, WI). Jasplakinolide was from Fisher Scientific (Pittsburgh, PA). $\quad \mathrm{N}^{\mathrm{G}}$-methyl-L-arginine acetate ( $\mathrm{L}$ NMMA), 2-phenyl-4,4,5,5-tetramethylimidazoline-1-oxyl 3-oxide (PTIO), S-nitroso-N-acetyl penicillamine (SNAP), curcumin, 8-(4-chlorophenylthio)-guanosine 3',5'-cyclic monophosphate sodium (8-PCPT-cGMP), and DT-2 were from Sigma. Rhodamine phalloidin was from Invitrogen (Carlsbad, CA). Tissue Protein Extraction reagent and Bicinchoninic Acid Protein Assay kit were from Pierce (Rockford, IL).

\section{Lung Fibroblast Isolation, Culture, Transfection, Sorting, and Treatment}

Human lung (myo)fibroblasts were established from tissue samples from patients undergoing lung transplantation for IPF, as approved by the Human Studies Committee of the University of Alabama at Birmingham. Lungs were minced in sterile PBS, and tissue pieces were placed in 100-mm tissue culture dishes containing Dulbecco's modified Eagle's medium (DMEM), 10\% fetal bovine serum (FBS), 1\% penicillin/streptomycin/glutamine, nonessential amino acids, and sodium pyruvate (supplemented DMEM). Medium was replenished every 3 days. After 14 days, cells growing out of the explants were trypsinized and plated in supplemented DMEM. Lung (myo)fibroblasts were used between passages 6 and 10.

Plasmid transfection was performed using a Nucleofector device (Amaxa, Inc., Cologne, Germany), as previously described. ${ }^{49}$ Cells expressing EGFP and EGFPtagged WT $\mathrm{MLC}_{20}$, DD-MLC 20 , RhoA ${ }^{\mathrm{V} 14}$, and RhoA ${ }^{\text {V14A188 }}$ were sorted using a FACSTARPlus Cell Sorter (Becton-Dickinson, Mountain View, CA) under sterile conditions.

Lung (myo)fibroblasts were grown in DMEM containing $10 \%$ FBS until $80 \%$ confluence. Cells were rinsed with
DMEM plus $0.1 \%$ FBS twice and were incubated in DMEM plus $0.1 \%$ FBS containing 1 to $100 \mathrm{nmol} / \mathrm{L}$ relaxin in the presence or absence of $100 \mu \mathrm{mol} / \mathrm{L}$ L-NMMA, 20 $\mu \mathrm{mol} / \mathrm{L} \mathrm{PTIO}, 100 \mu \mathrm{mol} / \mathrm{L}$ SNAP, $200 \mu \mathrm{mol} / \mathrm{L}$ 8-PCPTCGMP, $1 \mathrm{nmol} / \mathrm{L}$ to $10 \mu \mathrm{mol} / \mathrm{L}$ forskolin, $30 \mu \mathrm{mol} / \mathrm{L}$ curcumin, or $1 \mu \mathrm{mol} / \mathrm{L}$ DT-2 for 24 hours.

\section{Wrinkle Assay}

The wrinkle assay for measurement of fibroblast contractility was performed as described in the previous studies. $^{6,50,51}$ Briefly, approximately $15 \mu \mathrm{L}$ of silicone monomer was applied onto 18-mm glass coverslips and allowed to spread for 30 minutes. The upper layer of silicone was polymerized by exposure of the coverslip to an open flame for 1.5 seconds. The silicone coverslips were placed into a 12-well plate and were equilibrated with $10 \mu \mathrm{g} / \mathrm{mL}$ collagen type I in serum-free DMEM media, sterilized by UV light exposure, and left overnight in the incubator at $37^{\circ} \mathrm{C}$. Cells $\left(10^{4} \mathrm{cells} / \mathrm{cm}^{2}\right)$ were plated onto silicone coverslips in DMEM containing $0.1 \%$ FBS in the presence or absence of $100 \mathrm{nmol} / \mathrm{L}$ relaxin for 24 hours. Cell contraction on deformable silicone substrates was assessed by the formation of wrinkles seen with a $\times 20$ objective on a Nikon Eclipse TE 300 microscope (Nikon Instruments Inc., Melville, NY). Wrinkling cells were calculated as a percentage of the total cells. Mean values were calculated from 10 random regions, and at least three independent experiments were performed.

\section{Immunofluorescence and Confocal Laser Scanning Microscopy}

To observe wrinkles and $\alpha$-SMA-containing stress fibers, silicone-coated coverslips were fixed in $4 \%$ paraformaldehyde in PBS for 20 minutes and permeabilized with $0.5 \%$ Triton X-100 in PBS for 10 minutes. Cells were incubated with anti- $\alpha$-SMA antibody at a concentration recommended by the manufacturer at room temperature for 1 hour. Fluorescein isothiocyanate-conjugated goat anti-mouse IgG1 was used as a secondary antibody. To stain F-actin, cells were incubated with rhodamine-conjugated phalloidin at room temperature for 1 hour in the dark. Nuclei were stained with DAPI. Results were imaged with a Zeiss LSM510 confocal microscope equipped with a digital color camera (AxioCam) and MetaMorph Imaging software (Universal Imaging Corp, Downingtown, PA).

\section{Measurement of NO Production}

NO production was evaluated by spectrophotometrical measurement of nitrite and nitrate accumulation in cell culture supernatants using a Nitric Oxide Detection kit (Assay Designs), according to the manufacturer's recommendations. Absorbance was measured at $546 \mathrm{~nm}$ using a microplate reader. Results are expressed as picomoles of total nitrite plus nitrate produced per $10^{6}$ cells. 


\section{Measurement of Intracellular cGMP and cAMP Production}

Intracellular cGMP/cAMP levels were determined by colorimetric competitive immunoassay using cGMP/CAMP Complete EIA kits (Assay Design). Cells were lysed in 0.1 $\mathrm{mol} / \mathrm{L} \mathrm{HCl}$ to stop endogenous phosphodiesterase activity and to stabilize the released cGMP/cAMP. Standards and samples were loaded into 96-well plates coated with goat anti-rabbit IgG. Plates were incubated with cGMP/ CAMP conjugated to alkaline phosphatase, followed by rabbit polyclonal antibodies to cGMP/cAMP. Plates were washed, leaving only bound cGMP/cAMP. pNpp substrate solution was added to generate yellow color when catalyzed by the alkaline phosphatase on the cGMP/ cAMP conjugates. Optical density was determined in a plate reader at $450 \mathrm{~nm}$. cGMP/cAMP levels were calculated from a standard curve.

\section{PKG and PKA Activity Assay}

PKG activity was assayed using a cGK Assay kit (MBL International, Woburn, MA). Briefly, cell lysates were diluted in kinase buffer and pipetted into the wells precoated with PKG-specific substrates. The amounts of phosphorylated substrates were measured by binding with a horseradish peroxidase-conjugated PKG substrate-specific antibody, which then catalyzed the conversion of the chromogenic substrate tetramethylbenzidine from a colorless solution to a yellow solution. The color is quantified by spectrophotometry at $450 \mathrm{~nm}$.

Protein kinase $A(P K A)$ activity was determined using a PepTag Assay (Promega). This assay uses brightly col- ored fluorescent peptide substrates, LRRASLG (Kemptide), highly specific for PKA. The phosphorylation of Kemptide by PKA alters the peptide's net charge from 1 to -1 . This change in the net charge of the substrate allows the phosphorylated and nonphosphorylated substrates to be rapidly separated on a $0.8 \%$ agarose gel. The phosphorylated substrates migrated toward the cathode, whereas the nonphosphorylated substrates migrated toward the anode. Gel was photographed under UV light. PKA activity was assessed by the intensity of phosphorylated substrates that migrated toward the cathode.

\section{Rho Kinase Activity Assay}

Rho kinase activity was assessed using the ROCK Activity Assay kit (Cell Biolabs, San Diego, CA). Plates were precoated with substrates corresponding to the C-terminus of MYPT1, which contains a threonine residue that was phosphorylated by ROCK. The specific detector antibody was horseradish peroxidase-conjugated anti-phospho-MYPT1 (AF20). The amount of phosphorylated substrates was measured by binding with horseradish peroxidase-conjugated AF20, which catalyzed the conversion of tetramethylbenzidine to a yellow solution. Results were quantified by a plate reader at $450 \mathrm{~nm}$.

\section{Subcellular Fractionation}

Subcellular fractionation was performed as previously described. ${ }^{52}$ Briefly, cells were lysed in buffer containing $20 \mathrm{mmol} / \mathrm{L}$ Tris, $\mathrm{pH}$ 7.5; $150 \mathrm{mmol} / \mathrm{L} \mathrm{NaCl} ; 1 \mathrm{mmol} / \mathrm{L}$

\section{IPF lung}

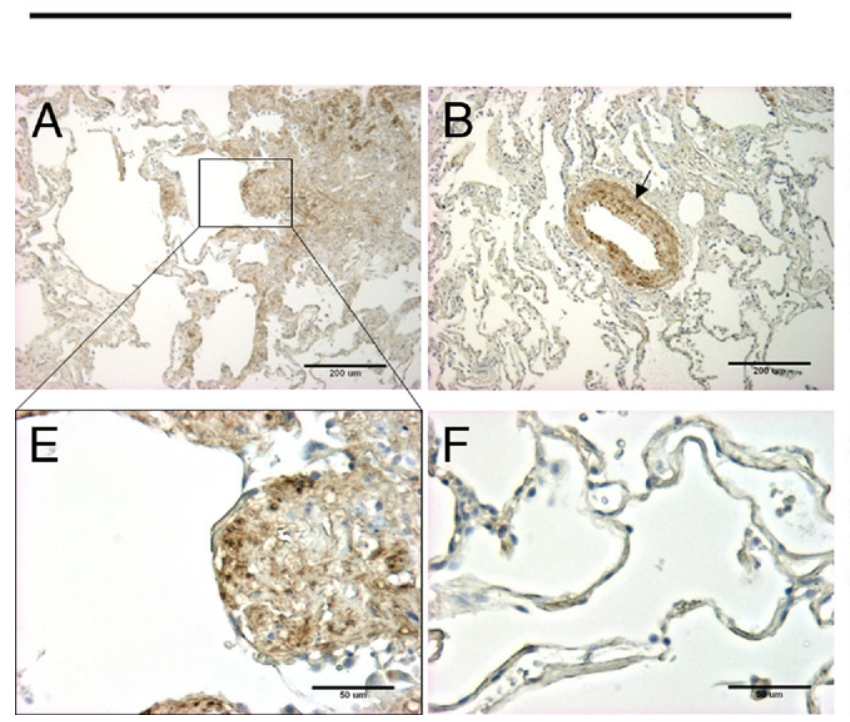

Mouse lung

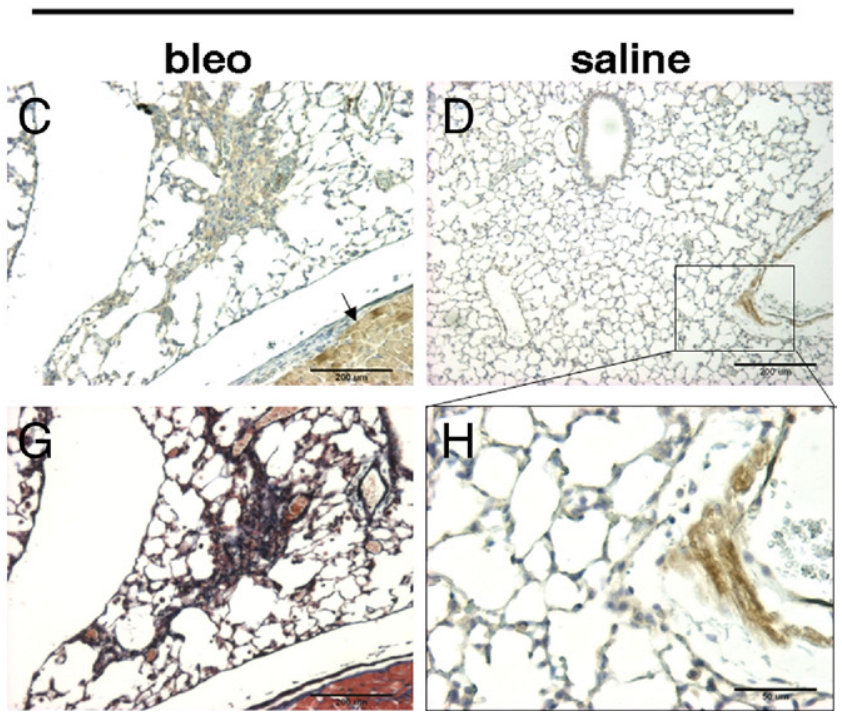

Figure 1. $M_{20}$ phosphorylation is prominent in both the fibroblastic foci in human IPF and in fibrotic regions in bleomycin-induced mouse lung fibrosis Paraffin-embedded human lung sections from patients with IPF (A, B, E, and $\mathbf{F})$ and mouse lung sections from bleomycin- or saline-treated mice ( $\mathbf{C}, \mathbf{D}$, G, and $\mathbf{H})$ were stained for phospho-MLC 20 (A-F and $\mathbf{H})$ or collagen (G, Masson's trichrome). A: A fibroblastic focus (boxed) and the surrounding area in human IPF. B: An arteriole expressing phospho-MLC 20 in SMCs of medial shown as a positive control (arrow). C: A fibrotic region in bleomycin-induced mouse lung fibrosis and adjacent areas; arrow indicates mouse myocardium expressing phospho-MLC 20 as a positive control. D: Saline-treated mouse lung, with the boxed area showing a part of the blood vessel wall. E: A magnified view of the fibroblastic focus shown in A. F: A relatively normal lung area in IPF. G: Masson's trichrome staining for the same area shown in $\mathbf{C}$. H: A magnified view of the boxed area shown in $\mathbf{D}$. Scale bars: $200 \mu \mathrm{m}(\mathbf{A}, \mathbf{B}$, and $\mathbf{E}-\mathbf{G}) ; 50 \mu \mathrm{m}(\mathbf{C}, \mathbf{D}$, and $\mathbf{H})$. 
EGTA; $10 \mathrm{mmol} / \mathrm{L} \mathrm{MgCl} ; 25 \mathrm{mmol} / \mathrm{L} \mathrm{NaF}$; and $1 \mathrm{mmol} / \mathrm{L}$ 4-amidinophenylmethanesulfonyl fluoride. Then, the cells were subjected to ultracentrifugation at 100,000 $\times g$ for 60 minutes. The supernatant was saved as the cytosolic fraction. The pellet was sonicated in the previously described buffer containing $1 \%$ Triton X-100 and centrifuged at $10,000 \times g$ for 30 minutes. The supernatant was saved as the membrane fraction.

\section{Co-Immunoprecipitation and Immunoblot Analysis}

Cells were rinsed three times with ice-cold PBS, $\mathrm{pH}$ 7.4 , and lysed with ice-cold cell lysis buffer $(20 \mathrm{mmol} / \mathrm{L}$ Tris, $\mathrm{pH} 7.5 ; 150 \mathrm{mmol} / \mathrm{L} \mathrm{NaCl} ; 1 \mathrm{mmol} / \mathrm{L}$ EDTA; 1 mmol/L EGTA; 1\% Triton X-100; $2.5 \mathrm{mmol} / \mathrm{L}$ sodium pyrophosphate; $1 \mathrm{mmol} / \mathrm{L} \quad \beta$-glycerophosphate; 1 $\mathrm{mmol} / \mathrm{L} \mathrm{Na} \mathrm{VO}_{4} ; 1 \mu \mathrm{g} / \mathrm{mL}$ leupeptin; and $1 \mathrm{mmol} / \mathrm{L}$ phenylmethylsulfonyl fluoride) for 5 minutes. After scraping, cell lysates were sonicated on ice three times for 5 seconds each and were centrifuged for 10 minutes at $12,000 \times g$ at $4^{\circ} \mathrm{C}$. Co-immunoprecipitation was performed with a ProFound Co-Immunoprecipitation Kit (Pierce, Rockford, IL), as previously described. ${ }^{49}$

Cell lysates containing 10 to $40 \mu \mathrm{g}$ total proteins were loaded onto SDS-polyacrylamide gels under reducing conditions. After electrophoresis, proteins were electrophoretically transferred from the gels to nitrocellulose at $100 \mathrm{~V}$ for 1.5 hours at $4^{\circ} \mathrm{C}$. Membranes were blocked in casein solution ( $1 \%$ casein and $25 \mathrm{mmol} / \mathrm{L}$ $\mathrm{Na}_{2} \mathrm{HPO}_{4}, \mathrm{pH}$ 7.1) for 1 hour at room temperature. Primary antibodies were diluted in Tris-buffered salinetween and casein solution (1:1) at a working concentration recommended by the manufacturers. Membranes were incubated with primary antibodies at room temperature for 1 hour. After extensive washing, membranes were incubated with peroxidase-conjugated secondary antibodies $(0.1 \mu \mathrm{g} / \mathrm{mL})$ diluted in Tris-buffered saline-tween for 1 hour at room temperature. Immunodetection was performed by chemiluminescence.

\section{Animals and Experimental Protocol}

Animal use and bleomycin protocols were approved by the Institutional Animal Care and Use Committee, University of Alabama at Birmingham. Pathogen-free female mice, aged 6 to 8 weeks, were used in this study. Relaxin KO mice and WT mice were generated from heterozygous parents (C57B/6J $\times$ 129SV background). Bleomycin sulfate (Almirall, Reinbek, Germany) was dissolved in sterile saline solution and intratracheally instilled into mice by a Stepper Repetitive Pipette (Tridak, DYMAX Corporation, Torrington, CT) as a single dose of $0.08 \mathrm{mg}$ in $50 \mu \mathrm{L}$ of saline solution per animal ( $5 \mathrm{U} / \mathrm{kg}$ body weight). Control mice received 50
A

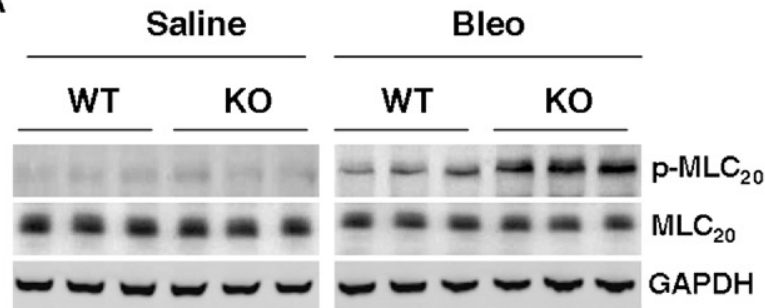

B Bleo

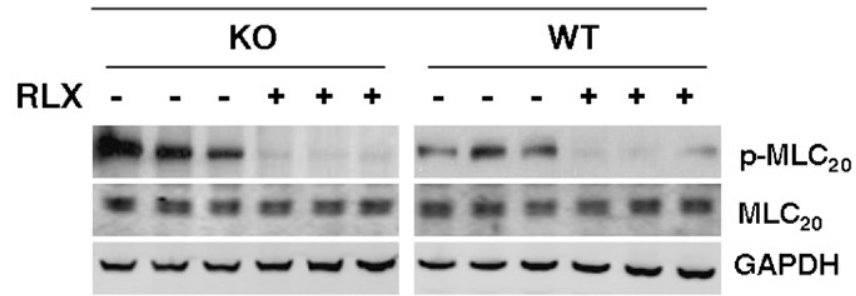

C

Saline

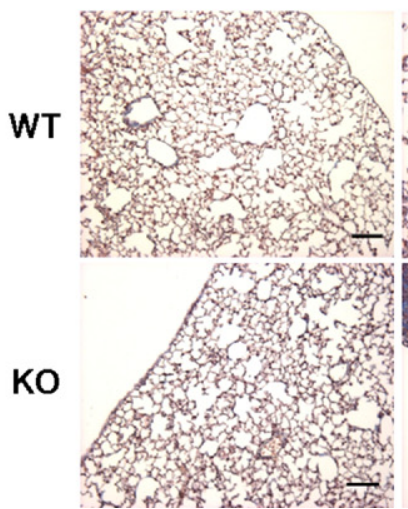

Bleo/PBS
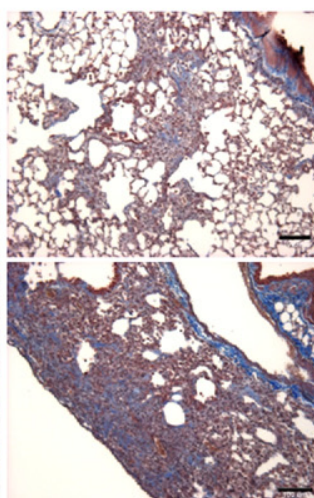

Bleo/RLX

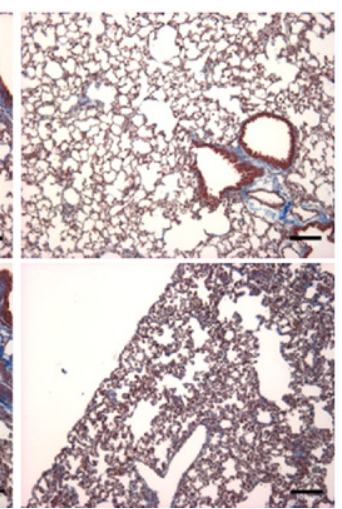

D

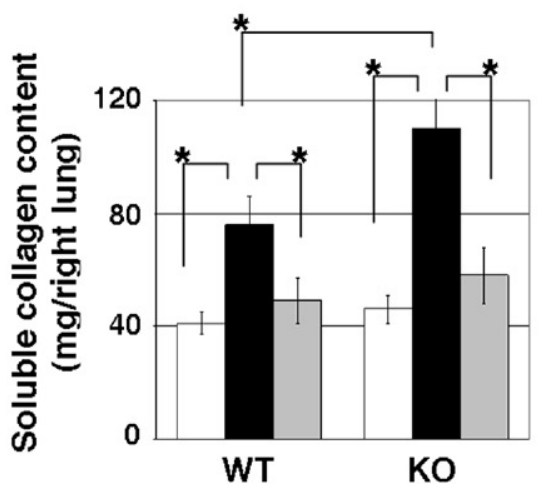

Figure 2. Relaxin (RLX) inhibits $M_{20}$ phosphorylation and lung fibrosis in a bleomycin (Bleo)-induced mouse model. A: Lungs isolated from Bleo- and saline-treated RLX KO and WT mice were homogenized. Levels of phospho-MLC 20 (p-MLC $\mathrm{M}_{20}$ ) and total MLC 20 in lung homogenates were determined by immunoblot analyses. GAPDH was used as the loading control. B: The RLX KO and WT mice were administered Bleo to induce lung fibrosis. At day 14 after lung injury, mice were given a continuous infusion of exogenous RLX or an equal volume of PBS (vehicle for RLX) through a s.c. implanted minipump for 7 days. Lungs were harvested at day 21. Levels of p-MLC 20 , total $\mathrm{MLC}_{20}$, and GAPDH were determined by immunoblot analyses. C: Masson's trichrome staining for collagen deposition in the saline and Bleo mouse groups treated with or without continuous infusion of exogenous RLX. Scale bars: $100 \mu \mathrm{m}$. D: Sircol-soluble collagen assay for mice treated as described in $\mathbf{C}\left(n \geq 5\right.$ mice per group). ${ }^{*} P<0.01$ for comparisons, as indicated 
$\mu \mathrm{L}$ of saline. For relaxin treatment, osmotic minipumps (model 1007D; Alzet, Cupertino, CA) filled with relaxin at a dosage of $0.5 \mathrm{mg} / \mathrm{kg}$ body weight/day over 7 days or an equal volume of PBS was S.c. implanted into mice, 14 days after bleomycin administration. ${ }^{30,49}$ Mice were sacrificed at 21 days. Lung tissues were excised and inflated with $4 \%$ (mass/volume) paraformaldehyde in PBS for histological and IHC analyses.

To prepare for lung homogenates, fresh lung tissues were transferred to prechilled tubes containing Tissue Protein Extraction reagent and Complete Mini Protease Inhibitor Cocktail (Roche, Indianapolis, IN) at a proportion of 1 tablet per $10 \mathrm{~mL}$ of Tissue Protein Extraction reagent and were homogenized at $4^{\circ} \mathrm{C}$. Homogenates were centrifuged at $9000 \times g$ for 10 minutes at $4^{\circ} \mathrm{C}$. Supernatants were transferred to clean microcentrifuge tubes. Total protein concentrations in the lung tissue homogenates were determined using a Bicinchoninic Acid Protein Assay kit.

\section{IHC and Histological Characteristics}

IHC was performed as previously described. ${ }^{49}$ Briefly, lung tissue sections ( $5 \mu \mathrm{m}$ thick) were immersed in 10 $\mathrm{mmol} / \mathrm{L}$ sodium citrate buffer $(\mathrm{pH} \mathrm{6.0)}$ and heated at $100^{\circ} \mathrm{C}$ for 10 minutes to unmask antigen. Sections were blocked with $5 \%$ normal goat serum and stained with anti-phospho-MLC 20 antibody at $2.5 \mu \mathrm{g} / \mathrm{mL}$. Endogenous peroxidase activity was quenched with $3 \% \mathrm{H}_{2} \mathrm{O}_{2}$. Staining was developed with biotinylated secondary antibodies, streptavidin-peroxidase, and 3-amino-9ethylcarbazole chromogen (Vector Laboratories, Burlingame, CA). Masson's trichrome staining for collagen was performed using a kit from Poly Scientific, accord-
IPF (myo)fibroblasts

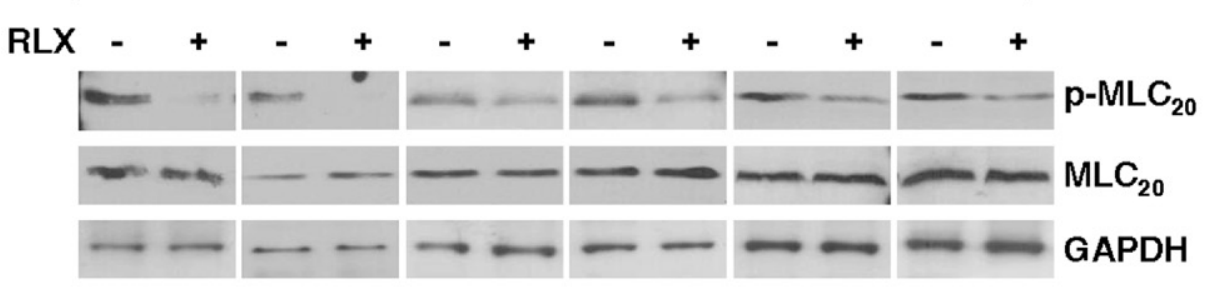

B

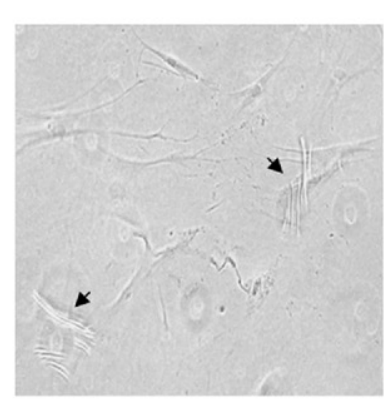

C
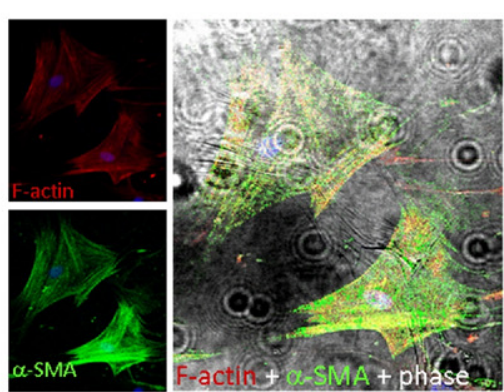

E

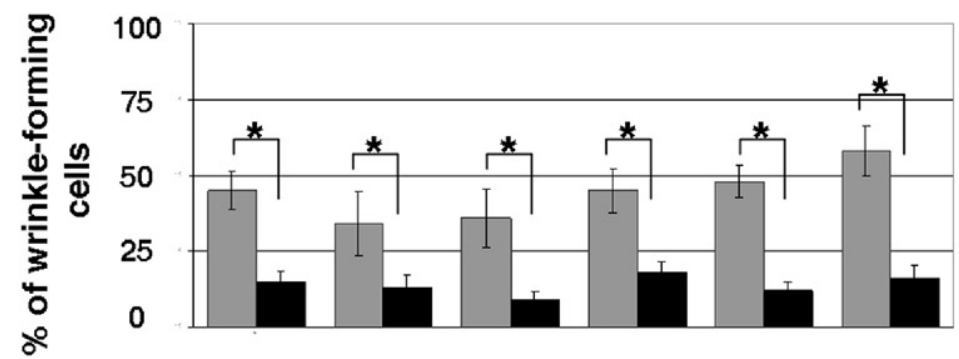

IPF myofibroblasts from 6 patients

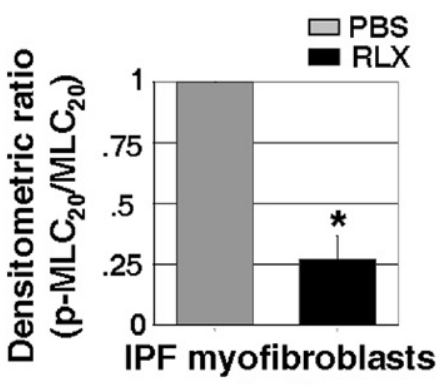

$(n=6)$

$\mathrm{D}$
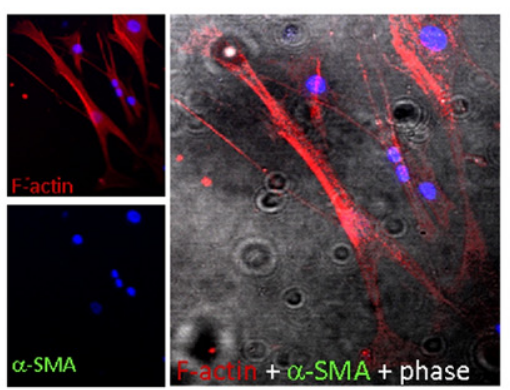

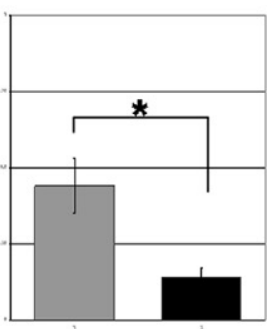

Average $(n=6)$

Figure 3. Relaxin (RLX) inhibits $M_{20}$ phosphorylation and contraction of lung myofibroblasts isolated from patients with IPF. A: Lung (myo)fibroblasts isolated from six human subjects with IPF were treated with $100 \mathrm{nmol} / \mathrm{L}$ RLX for 24 hours. Levels of p-MLC and total MLC $_{20}$ in cell lysates were determined by immunoblot analyses. GAPDH was used as a loading control. Relative p- MLC $_{20}$ levels were determined by scanning densitometry of the blots and normalized to total MLC 20 levels. The level of $\mathrm{p}-\mathrm{MLC}_{20}$ at baseline was set at $1 .{ }^{*} P<0.01(n=6)$. B: (Myo)fibroblasts of IPF, $1 \times 10^{4}$ cells $/ \mathrm{cm}^{2}$, were plated on silicone substrates prepared on an 18-mm coverslip and cultured in a 12-well plate for 24 hours. Wrinkles were observed and imaged under a microscope equipped with a digital camera. Arrows indicate wrinkle-forming cells. C and D: IPF (myo)fibroblasts cultured on silicone substrates were fixed and stained for $\alpha$-SMA with fluorescein isothiocyanate-conjugated anti- $\alpha$-SMA antibody (green) and F-actin with rhodamine-conjugated phalloidin (red). Phase-contrast and confocal immunofluorescent images were taken and overlaid to show the correlation between $\alpha$-SMA expression and wrinkle formation. E: IPF (myo)fibroblasts from six patients with IPF were cultured on silicone substrates in the presence of $100 \mathrm{nmol} / \mathrm{L}$ RLX or an equal volume of PBS (vehicle control for RLX) for 24 hours. Wrinkle-forming cells were counted and calculated as percentage of total cells. Results are the mean \pm SD of three separate experiments, with each experiment performed by random selection of 10 different regions. ${ }^{*} P<0.01$ for comparisons, as indicated. 
ing to the manufacturer's recommendations. Images were obtained with a Nikon Eclipse TE 300 microscope equipped with a Spot Insight CCD camera and MetaMorph software, version $6.2 \mathrm{r} 4$.

\section{Collagen Content Assay}

Levels of collagen in lung tissues were determined by the Sircol collagen assay (Biocolor Ltd, Newtownabbey, UK). Briefly, mouse right lungs were homogenized and collagen was solubilized in $0.5 \mathrm{~mol} / \mathrm{L}$ acetic acid containing $0.6 \%$ pepsin at $4^{\circ} \mathrm{C}$ overnight. After centrifugation at $15,000 \times g$ for 15 minutes, extracts were incubated with Sirius red dye. Absorbance was determined at $540 \mathrm{~nm}$ with a spectrophotometer (Eppendorf, Hauppauge, NY). Collagen content was expressed as micrograms per right lung. ${ }^{53}$

\section{Statistical Analysis}

Statistical differences among treatment conditions were determined using one-way analysis of variance (Newman-Keuls method for multiple comparisons). The analysis was performed with SigmaStat 3.0 software (SPSS Inc., Chicago, IL). $P<0.01$ was considered significant.

\section{Results}

Phosphorylation of $\mathrm{MLC}_{20}$ Is Prominent in Both the Fibroblastic Foci of Human IPF and Fibrotic Regions of the Murine Lung Injured by

\section{Intratracheal Bleomycin}

$\mathrm{MLC}_{20}$ phosphorylation regulates both muscle and nonmuscle cell contraction. ${ }^{2}$ To determine whether increased cell contractility is associated with lung fibrosis in vivo, we performed IHC staining to analyze $\mathrm{MLC}_{20}$ phosphorylation in paraffin-embedded lung tissue sections isolated from patients with IPF and in bleomycininjured mice. Staining for phospho-MLC 20 was prominent in the fibroblastic foci, in which myofibroblasts are predominant, in human IPF lungs and in fibrotic regions of bleomycin-injured mouse lungs (Figure 1, A, C, E, and $\mathrm{G}$ ). The relatively normal lung areas in IPF patients and saline-treated mice showed no significant alveolar phospho- $\mathrm{MLC}_{20}$ staining (Figure 1, D, F, and $\mathrm{H}$ ). The arterial smooth muscle, myocardium, and vascular adventitial layer were also positive for phospho-MLC 20 (Figure 1, B-D and $\mathrm{H}$ ), serving as positive controls for staining with this antibody. Tissue sections stained for nonimmune IgG were negative (data not shown). To our knowledge, these data provide the first in vivo evidence that $\mathrm{MLC}_{20}$, a contraction-associated protein, is phosphorylated and activated in fibrotic regions of IPF lung and bleomycin-injured mouse lung.
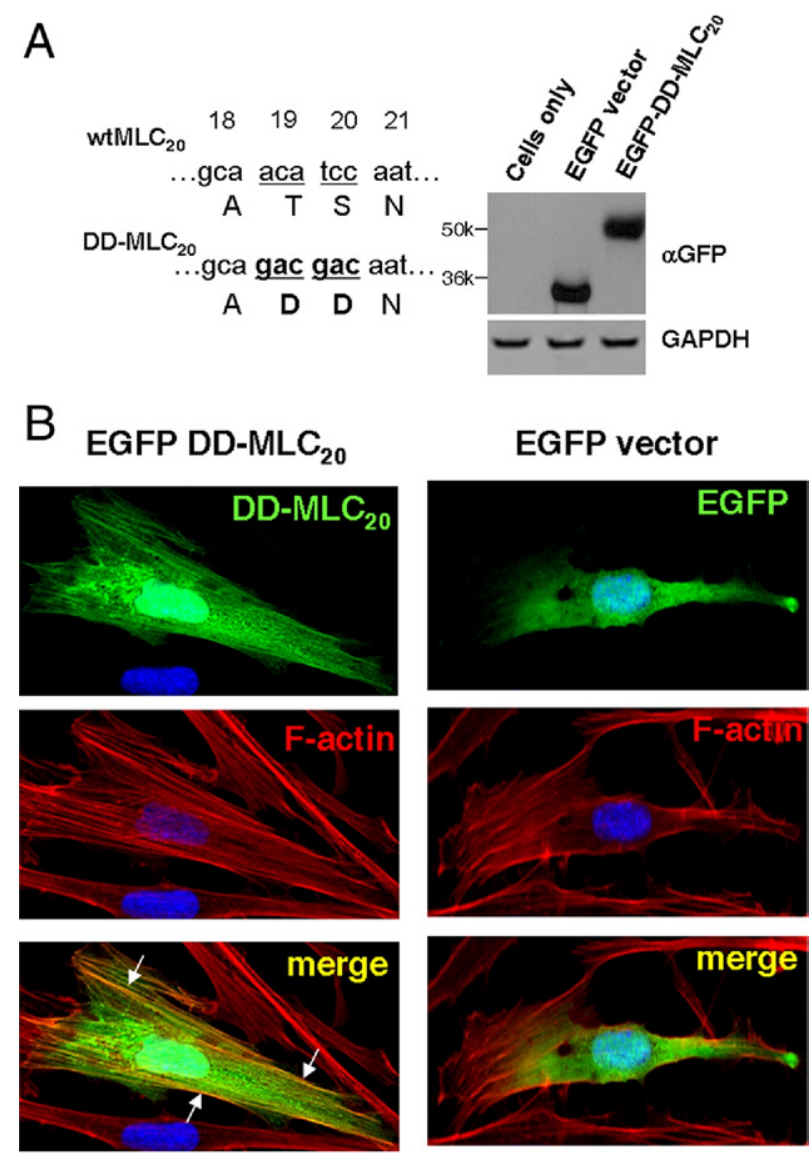

C

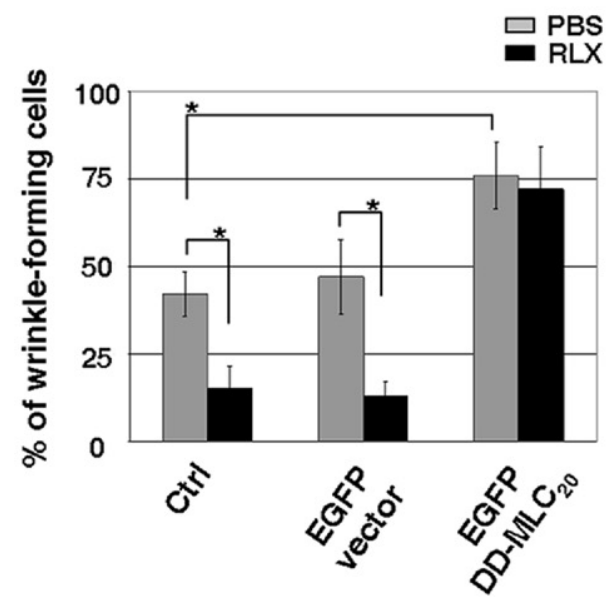

Figure 4. Overexpression of phosphomimetic DD-MLC ${ }_{20}$ blocks relaxin (RLX)-induced lung myofibroblast relaxation. A: IPF (myo)fibroblasts were transfected with EGFP-DD-MLC 20 or EGFP vector alone. Wild-type (wt, underlined letters) and mutated (DD, underlined and bold letters) $\mathrm{MLC}_{20}$ DNA and amino acid sequences are shown. Overexpression of EGFP-DD-MLC 20 and EGFP was confirmed by immunoblot analyses. GAPDH was used as a loading control. B: IPF (myo)fibroblasts transfected with EGFP-DD-MLC 20 or EGFP vector alone were incubated with rhodamine-conjugated phalloidin to stain F-actin (red). DAPI was used to stain nuclei (blue). Colocalization of DD-MLC 20 (green) and F-actin was observed with confocal laser scanning microscopy. Arrows indicate DD$\mathrm{MLC}_{20}$-containing stress fibers. C: Nontransfected IPF (myo)fibroblasts (Ctrl), EGFP-expressing IPF (myo)fibroblasts, and EGFP-DD-MLC 20 -expressing IPF (myo)fibroblasts were cultured on silicone substrates in the presence of $100 \mathrm{nmol} / \mathrm{L}$ RLX or an equal volume of PBS (vehicle control) for 24 hours. Cell contraction was determined by wrinkle assay. Results are the mean $\pm \mathrm{SD}$ of three separate experiments, each performed from 10 random regions. ${ }^{*} P<0.01$ for comparisons, as indicated. 
Relaxin Is an Endogenous Inhibitor of $\mathrm{MLC}_{20}$ Phosphorylation and Lung Fibrosis in the Bleomycin Mouse Model

To determine the effect of relaxin on $\mathrm{MLC}_{20}$ phosphorylation in a murine model of lung injury and fibrosis, lungs of relaxin $\mathrm{KO}$ and WT mice were injured by intratracheal instillation of the chemotherapeutic agent, bleomycin. Control mice were administered saline. A subgroup of bleomycin-injured mice was given continuous infusions of recombinant relaxin or PBS with s.c. implanted minipumps on days 14 to 21 after bleomycin injury. Lungs were harvested on day 21. Immunoblot analyses showed that saline-treated relaxin $\mathrm{KO}$ mice and WT mice expressed low levels of phospho-MLC $\mathrm{C}_{20}$ in the lung. Elevated phospho-MLC 20 levels were observed in both $\mathrm{KO}$ and WT mice injured with bleomycin (Figure 2A). Compared to WT mice, KO mice had a higher level of phospho-MLC ${ }_{20}$ in response to bleomycin (Figure 2A). The continuous infusion of exogenous relaxin for 7 days inhibited bleomycin-induced $\mathrm{MLC}_{20}$ phosphorylation in both $\mathrm{KO}$ and WT mice (Figure 2B). Masson's trichrome staining showed that bleomycin-injured KO mice had more extensive collagen deposition in the lung compared with bleomycin-injured WT mice. Relaxin infusion attenuated collagen deposition in the lungs of both KO and WT mice; these data suggest that relaxin is an endogenous inhibitor of $\mathrm{MLC}_{20}$ phosphorylation and lung fibrosis in vivo.

\section{Relaxin Inhibits $\mathrm{MLC}_{20}$ Phosphorylation and Attenuates Contraction of Myofibroblasts Isolated from the Lungs of Patients with IPF}

To determine the effect of relaxin on $\mathrm{MLC}_{20}$ phosphorylation and contraction of human lung myofibroblasts, we treated lung (myo)fibroblasts isolated from six patients
A
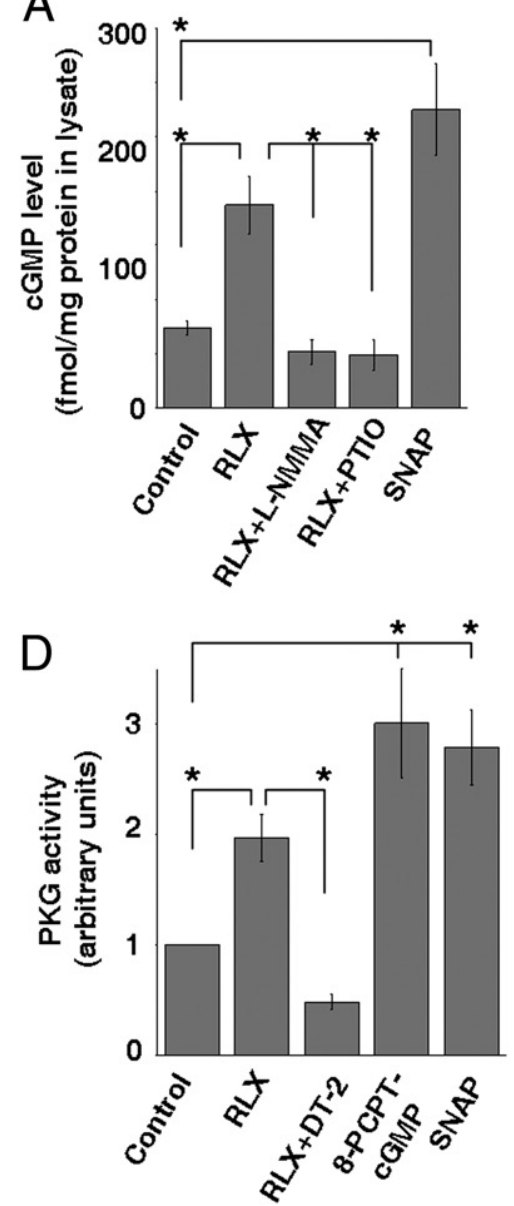

B

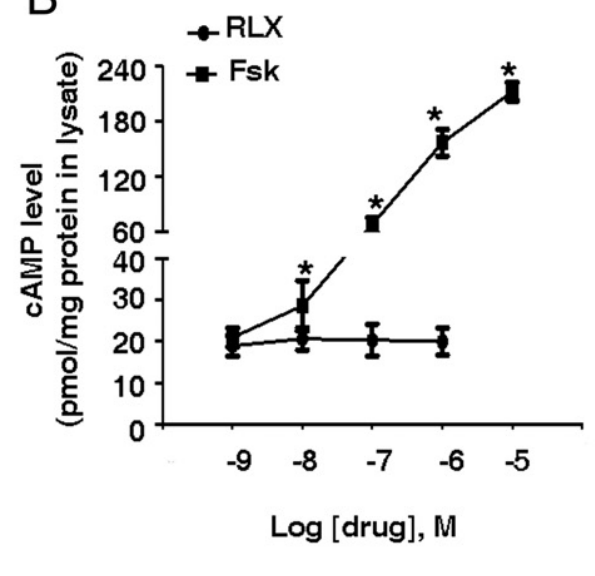

$E$

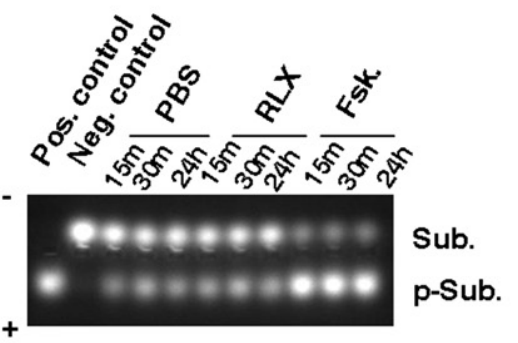

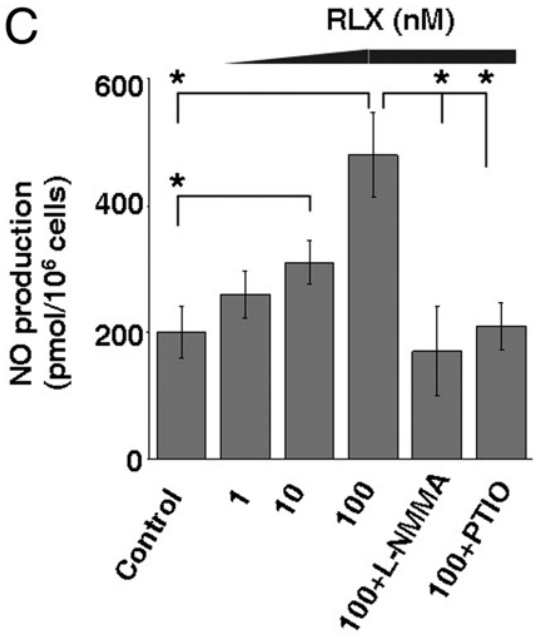

$\mathrm{F}$

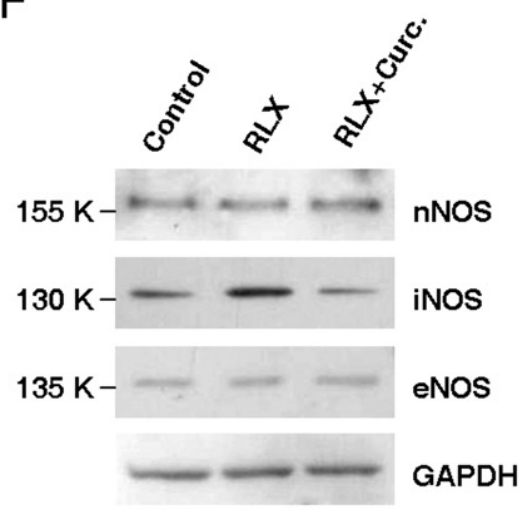

Figure 5. Relaxin (RLX) promotes NO/cGMP/PKG signaling in IPF (myo)fibroblasts. A: Subconfluent IPF (myo)fibroblasts were treated with 100 nmol/L RLX, 100 $\mu \mathrm{mol} / \mathrm{L}$ SNAP, and $100 \mathrm{nmol} / \mathrm{L}$ RLX in the presence of $100 \mu \mathrm{mol} / \mathrm{L}$ L-NMMA or $20 \mu \mathrm{mol} / \mathrm{L}$ PTIO for 24 hours. Intracellular cGMP levels were determined by colorimetric competitive immunoassay. B: IPF (myo)fibroblasts were treated with $1 \mathrm{nmol} / \mathrm{L}$ to $1 \mu \mathrm{mol} / \mathrm{L}$ of RLX or $1 \mathrm{nmol} / \mathrm{L}$ to $10 \mu \mathrm{mol} / \mathrm{L}$ of forskolin (Fsk) for 24 hours. Intracellular cAMP levels were determined by colorimetric competitive immunoassay. C: IPF (myo)fibroblasts were treated with 1 to 100 nmol/L of RLX in the presence or absence of $100 \mu \mathrm{mol} / \mathrm{L} \mathrm{L}$-NMMA or $20 \mu \mathrm{mol} / \mathrm{L}$ PTIO for 24 hours. NO production in supernatants was measured by nitrite and nitrate accumulation. D: IPF (myo)fibroblasts were treated with $100 \mathrm{nmol} / \mathrm{L}$ RLX in the presence or absence of $1 \mu \mathrm{mol} / \mathrm{L}$ DT-2 or $200 \mu \mathrm{mol} / \mathrm{L}$ 8-PCPT-cGMP or with 100 $\mu \mathrm{mol} / \mathrm{L}$ SNAP for 24 hours. PKG activity was measured by colorimetric immunoassay. E: IPF (myo)fibroblasts were treated with PBS, 100 nmol/L RLX, or $1 \mu$ mol/L Fsk for various times, as indicated. Cell lysates were incubated with PKA-specific substrates. Phosphorylated substrates (p-Sub) and nonphosphorylated substrates (Sub) were separated on a $0.8 \%$ agarose gel and used for evaluating PKA activity. F: IPF (myo)fibroblasts were treated with 100 nmol/L RLX in the presence or absence of $30 \mu \mathrm{mol} / \mathrm{L}$ curcumin (Curc) for 24 hours. Levels of nNOS, iNOS, and eNOS were determined by immunoblot analyses. Results are the mean \pm SD of three separate experiments. ${ }^{*} P<0.01$ for comparisons, as indicated. 
with IPF with relaxin for 24 hours. Relaxin treatment decreased levels of phospho-MLC 20 in all IPF (myo)fibroblasts (Figure 3A). Next, we evaluated cellular contractility using the wrinkle assay, ${ }^{6}$ in which contractility is determined by the percentage of cells that form wrinkles on flexible silicone substrates (Figure 3B). Unlike the commonly used fibroblast-populated collagen gel assay, which measures averaged contractile strength exerted by a cell population, the wrinkle assay measures contraction on a single-cell basis. By using this approach in combination with immunofluorescent staining techniques, we showed that, among heterogeneous IPF fibroblasts, wrinkle-forming cells were primarily $\alpha$-SMA-positive myofibroblasts (Figure $3 \mathrm{C}$ ), whereas most cells that do not form wrinkles were $\alpha$-SMA negative (Figure 3D); this suggests that the subset of IPF fibroblasts that are contractile is of the myofibroblastic phenotype. The wrinkle assay showed that relaxin treatment decreased the contractile capacity of most wrinkle-forming IPF lung myofibroblasts (Figure 3E), suggesting that relaxin inhibits signaling of the contractile response in human IPF lung myofibroblasts.

\section{Ectopic Expression of a Phosphomimetic $M L C_{20}$ Mutant Blocks the Capacity of Relaxin to Inhibit Contractility of Human IPF Myofibroblasts}

Next, we determined whether relaxin-induced $\mathrm{MLC}_{20}$ dephosphorylation is essential for its inhibitory effect on IPF myofibroblast contractility. Previous studies ${ }^{48,54,55}$ have shown that a mutant $\mathrm{MLC}_{20}$, in which the phosphorylation target serine and threonine residues are replaced with aspartic acids (DD-MLC ${ }_{20}$ ), is phosphomimetic and functions as a constitutively active $\mathrm{MLC}_{20}$ in porcine kidney epithelial cells and cervical cancer cells. In this study, we generated $\mathrm{MLC}_{20}$ mutant plasmids that express the same DD-MLC ${ }_{20}$ construct as an N-terminal-tagged EGFP fu- sion protein and transfected this plasmid into IPF (myo)fibroblasts. Immunoblot analyses showed that transfected IPF cells expressed EGFP-DD-MLC 20 at the expected molecular mass (50 kDa) (Figure 4A). Immunofluorescent analyses showed that EGFP-DD-MLC 20 fusion proteins incorporated into thick stress fibers, whereas EGFP alone did not (Figure 4B), suggesting that DD-MLC ${ }_{20}$ is structurally integrated into the actomyosin system of myofibroblasts. Ectopic expression of phosphomimetic DD-MLC 20 by IPF (myo)fibroblasts abrogated the inhibitory effect of relaxin on lung myofibroblast contraction (Figure 4C). These data suggest that relaxin regulation of myofibroblast contractility targets an intermediary step upstream of $\mathrm{MLC}_{20}$ phosphorylation. Furthermore, overexpression of DD-MLC 20 significantly increased IPF myofibroblast contraction compared with nontransfected control cells or cells expressing EGFP alone (Figure $4 \mathrm{C}$ ). Together, these findings indicate that $\mathrm{MLC}_{20}$ dephosphorylation mediates myofibroblast relaxation and that the effect of relaxin on myofibroblast relaxation is regulated by signaling upstream of $\mathrm{MLC}_{20}$ phosphorylation.

Relaxin activates the NO/cGMP/PKG signaling pathway in IPF (myo)fibroblasts and regulates multiple cell signaling pathways. ${ }^{25}$ Of these, the CAMP/PKA- and NO/ cGMP/PKG-dependent pathways regulate cell contraction. ${ }^{56-60}$ We determined whether CAMP/PKA and NO/ cGMP/PKG signals are involved in relaxin-induced IPF lung myofibroblast relaxation. Relaxin treatment increased the level of intracellular cGMP by 2.5 -fold, and the NO synthase inhibitors, L-NMMA and PTIO, inhibited relaxin-induced cGMP production; SNAP, an NO donor, promoted cGMP production by IPF (myo)fibroblasts (Figure $5 \mathrm{~A}$ ). In contrast, relaxin ( $1 \mathrm{nmol} / \mathrm{L}$ to $1 \mu \mathrm{mol} / \mathrm{L}$ ) did not induce significant changes in cAMP production, whereas forskolin, an adenylyl cyclase activator, induced a dosedependent increase in cAMP production (Figure 5B).
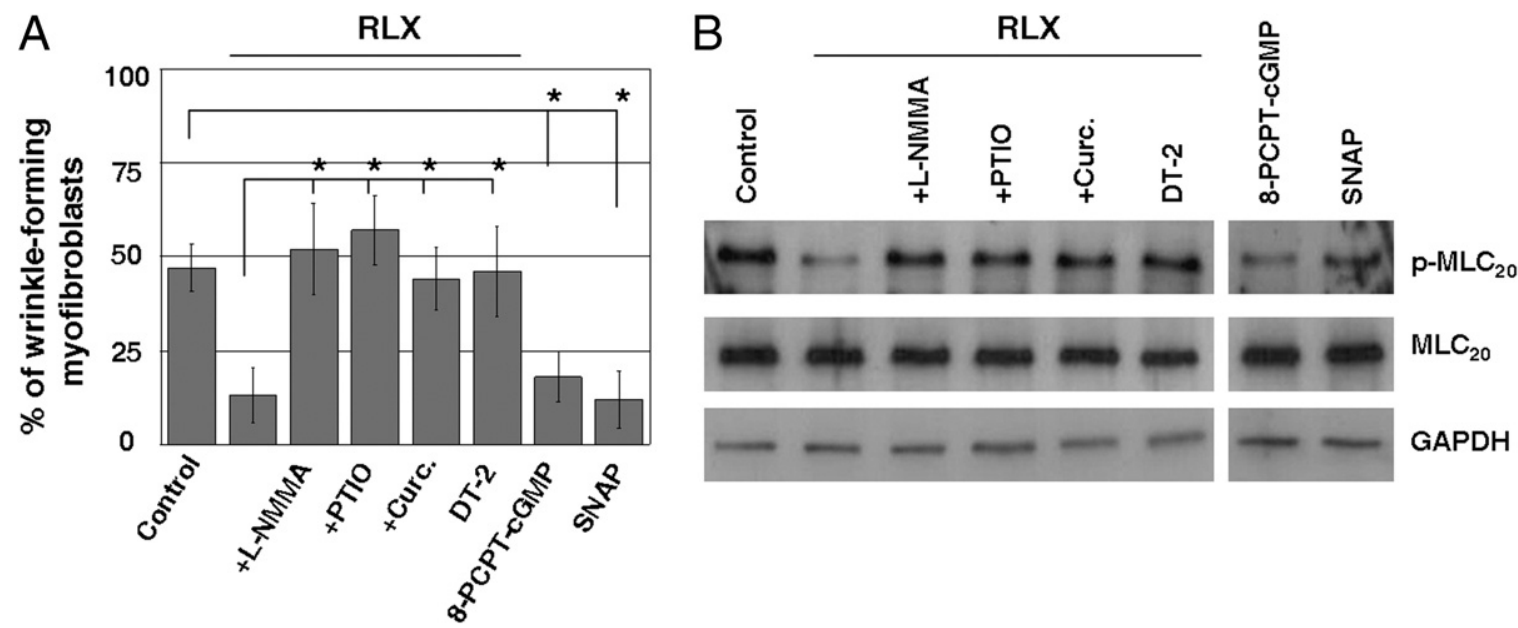

Figure 6. Blocking NO/cGMP/PKG signaling inhibits relaxin (RLX)-induced MLC 2 dephosphorylation and lung myofibroblast relaxation. A: IPF (myo)fibroblasts were cultured on silicone substrates and treated with $100 \mathrm{nmol} / \mathrm{L}$ RLX, $200 \mu \mathrm{mol} / \mathrm{L} 8-\mathrm{PCPT}-\mathrm{cGMP}, 100 \mu \mathrm{mol} / \mathrm{L}$ SNAP, and $100 \mathrm{nmol} / \mathrm{L}$ RLX in the presence of 100 $\mu \mathrm{mol} / \mathrm{L}$ L-NMMA, $20 \mu \mathrm{mol} / \mathrm{L}$ PTIO, $30 \mu \mathrm{mol} / \mathrm{L}$ curcumin (Curc.), or $1 \mu \mathrm{mol} / \mathrm{L}$ DT-2 for 24 hours. Cell contraction was measured by the wrinkle assay. Results are the mean $\pm \mathrm{SD}$ of three separate experiments, each performed from 10 random regions. ${ }^{*} P<0.01$ for comparisons, as indicated. B: Subconfluent IPF (myo)fibroblasts were treated as previously described. Levels of $\mathrm{p}-\mathrm{MLC}_{20}$ and total $\mathrm{MLC}_{20}$ were determined by immunoblot analyses. GAPDH was used as a loading control. 
Relaxin promoted a dose-dependent increase in NO synthesis, and L-NMMA and PTIO blocked relaxin-induced NO production in IPF (myo)fibroblasts (Figure 5C). In addition, relaxin elevated PKG activity by 2.0 -fold in the same cells (Figure 5D). DT-2, a cell-permeable PKG inhibitor, inhibited relaxin-induced PKG activation; 8-PCPTcGMP, an analog of the natural cGMP signal molecule, and SNAP (both serving as positive controls) promoted PKG activation (Figure 5D). Relaxin had no effect on PKA activity, whereas forskolin (which increases cAMP production; positive control) induced PKA activation (Figure $5 \mathrm{E})$, corroborating the earlier finding that relaxin does not signal via CAMP production in IPF (myo)fibroblasts.

Relaxin increased inducible NO synthase (iNOS or NOS II) expression in IPF (myo)fibroblasts; neither neuronal NOS (nNOS or NOS I) nor endothelial NOS (eNOS or NOS III) expression was affected by relaxin treatment (Figure 5F). Curcumin, a plant extract known to inhibit iNOS expression by preventing the nuclear import of $\mathrm{NF}-\kappa \mathrm{B},{ }^{61}$ abrogated relaxin-induced iNOS expression. These data indicate that, in IPF (myo)fibroblasts, relaxin promotes NO production by up-regulation of iNOS. Together, our data suggest that relaxin signals via the NO/cGMP/PKG, not the CAMP/PKA, pathway in IPF (myo)fibroblasts.

\section{Blocking NO/cGMP/PKG Signal Transduction Abrogates the Ability of Relaxin to Inhibit $M L C_{20}$ Phosphorylation and Lung Myofibroblast Contraction}

To determine whether the NO/cGMP/PKG pathway mediates relaxin inhibition of IPF lung myofibroblast contraction, we treated IPF (myo)fibroblasts cultured on silicone substrates with or without relaxin in the presence or absence of NO/cGMP/PKG signaling antagonists, L-NMMA, PTIO, curcumin, and DT-2. Blocking NO/cGMP/PKG signal transduction with these antagonists abrogated relaxin-induced lung myofibroblast relaxation, whereas activation of NO/cGMP/ PKG signaling with 8-PCPT-cGMP and SNAP promoted IPF lung myofibroblast relaxation (Figure 6A). These data sug-
A

A
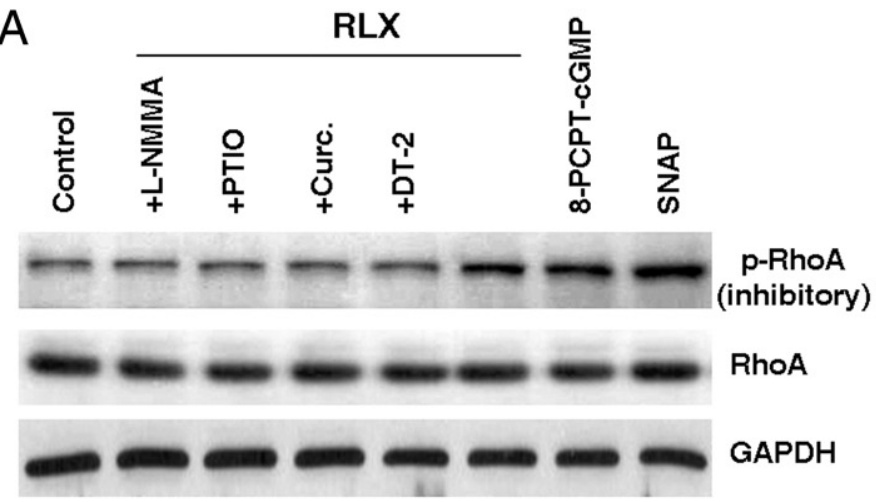

RhoA

GAPDH
B
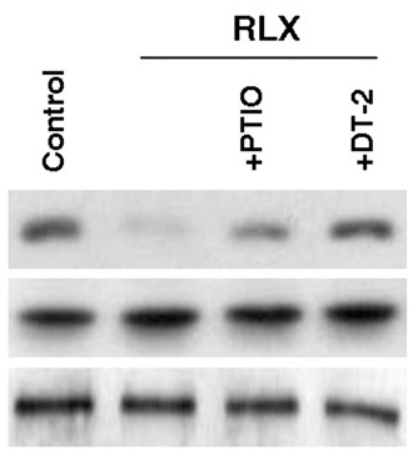

RhoA - membrane (active)
C

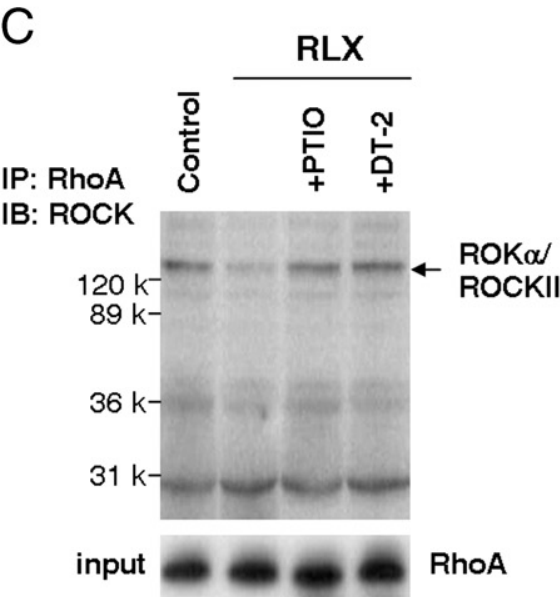

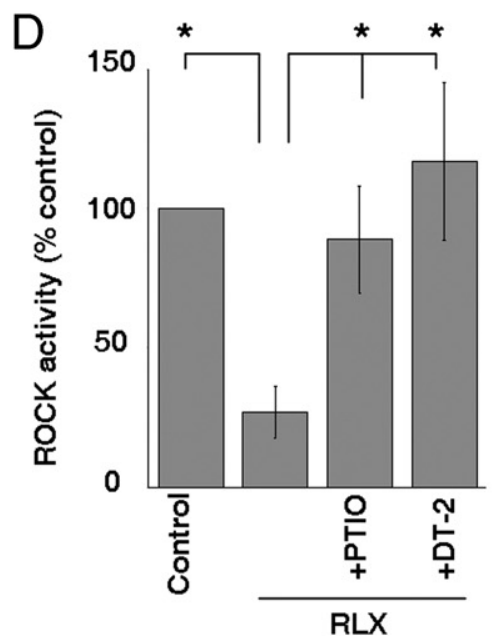

E

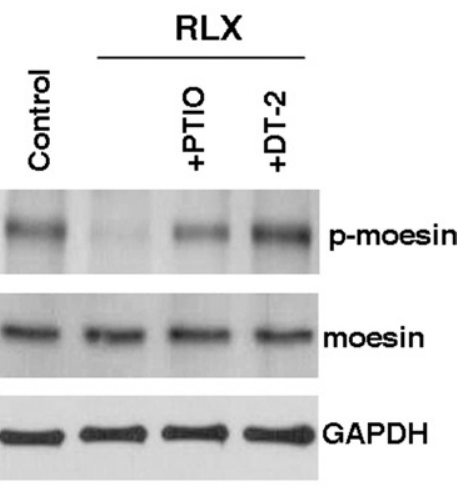

Figure 7. Relaxin (RLX)-induced NO/CGMP/PKG activation promotes RhoA phosphorylation at Ser188, leading to RhoA/ROCK inactivation. A: Subconfluent IPF (myo)fibroblasts were treated with RLX in the presence or absence of NO/cGMP/PKG antagonists or agonists, as indicated. Cells were lysed, and levels of phospho-RhoA at Ser188 (p-RhoA) and total RhoA (RhoA) were determined by immunoblot analyses. GAPDH was used as a loading control. B: Subconfluent IPF (myo)fibroblasts were treated with RLX in the presence or absence of PTIO or DT-2 for 24 hours. Cytosolic and membrane proteins were fractionated. Levels of RhoA from the cytosolic and membrane fractions were determined by immunoblot analyses. GAPDH was used as a loading control. C: IPF (myo)fibroblasts were treated as described in B. Cells were lysed, and cell lysates were immunoprecipitated with anti-RhoA antibody. Immunoprecipitated proteins were blotted with anti-ROK $\alpha /$ ROCK II antibody. A portion of cell lysates was immunoblotted for RhoA levels in cell lysates (input) for loading control. D: An ROCK activity assay was performed by incubation of cell lysates with an ROCK-specific substrate, MYPT1, followed by a colorimetric immunoassay. The level of ROCK activity from cells without any treatments (control) was set at 100\%. Results are the mean $\pm \mathrm{SD}$ of three separate experiments. ${ }^{*} P<0.01$ for comparisons. E: IPF (myo)fibroblasts were treated as described in $\mathbf{B}$. Cells were lysed, and levels of phospho-moesin (Thr558) (p-moesin) and total moesin were determined by immunoblot analyses. GAPDH was used as a loading control. 
gest that NO/cGMP/PKG signaling mediates relaxin inhibition of IPF lung myofibroblast contraction.

By demonstrating that the induction of $\mathrm{MLC}_{20}$ dephosphorylation is essential for the inhibitory effect of relaxin on IPF myofibroblast contraction, we next determined whether the NO/cGMP/PKG signaling mediates relaxinregulated $\mathrm{MLC}_{20}$ dephosphorylation. The augmentation of NO/cGMP/PKG signaling by 8-PCPT-cGMP and SNAP induced $\mathrm{MLC}_{20}$ dephosphorylation, whereas relaxin-induced $\mathrm{MLC}_{20}$ dephosphorylation was blocked by L-NMMA, PTIO, curcumin, and DT-2 (Figure 6B). These data suggest that the NO/cGMP/PKG signaling pathway mediates relaxin regulation of $\mathrm{MLC}_{20}$ dephosphorylation and IPF lung myofibroblast relaxation.

\section{Relaxin-Induced NO/cGMP/PKG Activation Promotes RhoA Phosphorylation at Ser188, Resulting in RhoA/ROCK Inactivation}

RhoA/ROCK signaling regulates myofibroblast contraction. ${ }^{2} \mathrm{MLC}_{20}$ phosphorylation, a downstream target of RhoA/ROCK signaling, is increased in the fibroblastic foci of IPF lungs (Figure 1, A and E), suggesting that lung myofibroblast contraction may be linked to RhoA/ROCK activation. The phosphorylation of RhoA at Ser188 inactivates RhoA, which uncouples the classic GDP/GTP cycle. ${ }^{62,63}$ Previous studies ${ }^{52,64,65}$ have shown that PKG promotes RhoA phosphorylation at Ser188, resulting in the inactivation of RhoA. Herein, we show that treatment of IPF (myo) fibroblasts with relaxin and NO/cGMP/PKG agonists (8-
PCPT-cGMP and SNAP) promoted RhoA phosphorylation at Ser188 (Figure 7A). NO/cGMP/PKG antagonists ( $L$ NMMA, PTIO, curcumin, and DT-2) blocked relaxin-induced RhoA phosphorylation (Figure 7A). Relaxin decreased the level of membrane-bound RhoA (by cellular fractionation analyses), which was reversed by the NO/ cGMP/PKG antagonists, PTIO and DT-2 (Figure 7B), suggesting that relaxin treatment induces RhoA translocation from a membrane-bound active form to a cytosolic inactive form. Immunoprecipitation studies showed that binding of RhoA to ROCK was decreased by relaxin in IPF (myo)fibroblasts (Figure 7C). Finally, relaxin decreased ROCK activity by an enzyme-linked immunosorbent assay that measures MYPT1 phosphorylation (Figure 7D) and by immunoblot analyses of ROCK-specific moesin phosphorylation at Thr558 (Figure 7E). The NO/cGMP/PKG antagonists, PTIO and DT-2, abrogated relaxin-induced ROCK inactivation (Figure 7, D and E). Together, these data suggest that the relaxin-activated NO/cGMP/PKG signaling pathway induces RhoA phosphorylation on Ser188, resulting in RhoA disassociation from ROCK and consequent ROCK inactivation.

Overexpression of Nonphosphorylable Constitutively Active RhoA (RhoA V14A188) Renders IPF Lung Myofibroblasts Resistant to Relaxin-Induced $M L C_{20}$ Dephosphorylation and Relaxation

To study the role of RhoA phosphorylation in relaxin regulation of lung myofibroblast relaxation, we constructed an EGFP-tagged, nonphosphorylable, constitutively ac-
A

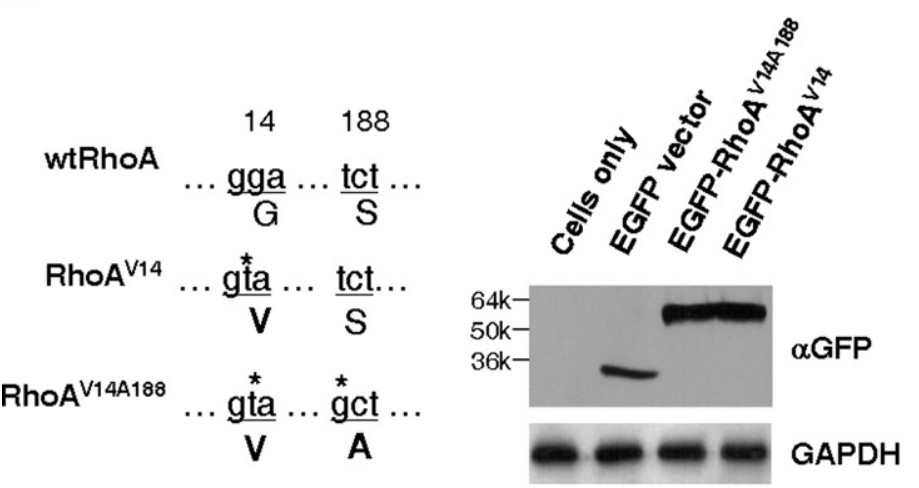

B

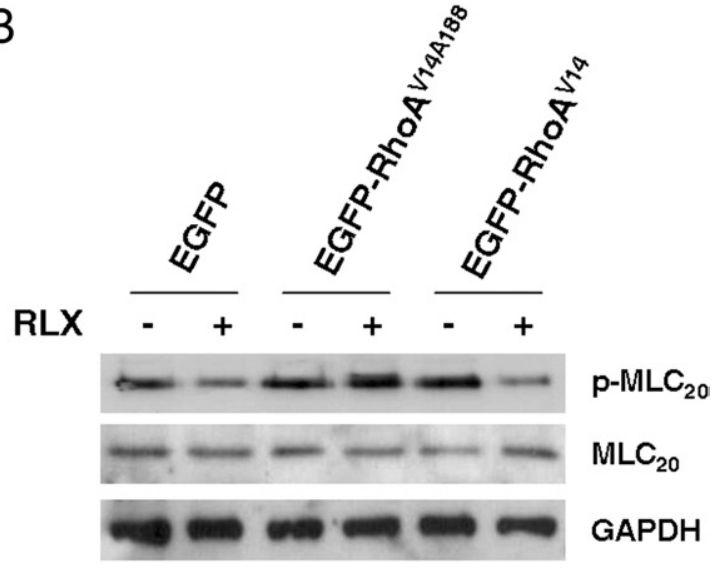

Figure 8. Overexpression of nonphosphorylable constitutively active RhoA ( RhoA $^{\mathrm{V} 14 \mathrm{~A} 188}$ ) renders IPF (myo)fibroblasts resistant to relaxin (RLX)-induced $\mathrm{MLC}_{20}$ dephosphorylation and relaxation. A: EGFP vector, EGFP-RhoA ${ }^{\mathrm{V} 14}$, and EGFP-RhoA ${ }^{\mathrm{V} 14 \mathrm{~A} 188}$ were transfected into IPF (myo)fibroblasts. Expression levels of EGFP and EGFP fusion proteins were determined by immunnoblot analyses. GAPDH was used as a loading control. B: IPF (myo)fibroblasts expressing EGFP, EGFP-RhoA 14 , and EGFP-RhoA 14 A188 were treated with or without $100 \mathrm{nmol} / \mathrm{L}$ RLX for 24 hours. Levels of p-MLC 20 and total $\mathrm{MLC}_{20}$ were determined by immunoblot analyses. GAPDH was used as a loading control. C: Cell contraction was measured using the wrinkle assay. Results are the mean $\pm \mathrm{SD}$ of three separate experiments, each performed from 10 random regions. ${ }^{*} P<0.01$ for comparisons, as indicated. 
tive RhoA (EGFP-RhoA ${ }^{\mathrm{V} 14 \mathrm{~A} 188}$ ) plasmid. The EGFPRho $A^{\mathrm{V} 14 \mathrm{~A} 188}$ plasmid, EGFP-tagged constitutively active RhoA (EGFP-RhoA ${ }^{\mathrm{V} 14}$ ) plasmid, or EGFP plasmid (control) was transfected into IPF (myo)fibroblasts (Figure $8 \mathrm{~A}$ ). As expected, overexpression of constitutively active RhoA increased $\mathrm{MLC}_{20}$ phosphorylation in IPF (myo)fibroblasts, compared with EGFP control (Figure 8B). Cells expressing EGFP-RhoA $\mathrm{A}^{\mathrm{V} 14}$ (constitutively active) and EGFP (control plasmid) responded to relaxin with decreased $\mathrm{MLC}_{20}$ phosphorylation; in contrast, cells expressing EGFP-RhoA ${ }^{\mathrm{V} 14 \mathrm{~A} 188}$ were resistant to relaxin-induced $\mathrm{MLC}_{20}$ dephosphorylation (Figure 8B). Consistent with the findings on $\mathrm{MLC}_{20}$ phosphorylation, the wrinkle assay showed that overexpression of both constitutively active RhoA plasmids increased IPF myofibroblast contractility (Figure $8 \mathrm{C}$ ). Relaxin attenuated myofibroblast contraction in both EGFP (control) cells and EGFPRho $A^{\mathrm{V} 14}$ (constitutively active, phosphorylable) cells. However, EGFP-RhoA V14A188 (constitutively active, nonphosphorylable) cells were resistant to relaxin-induced myofibroblast relaxation. These results demonstrate that RhoA Ser188 phosphorylation mediates relaxin-induced $\mathrm{MLC}_{20}$ dephosphorylation and IPF myofibroblast relaxation.

\section{Discussion}

In this study, we elucidated a novel antifibrotic mechanism of relaxin via the inhibition of myofibroblast contractility. This antifibrotic action of relaxin is transduced by increasing intracellular cGMP levels through an iNOS-dependent mechanism and downstream activation of PKG, which phosphorylates RhoA. RhoA phosphorylation inactivates ROCK. ROCK inactivation induces $\mathrm{MLC}_{20}$ dephosphorylation, leading to myofibroblast relaxation (Figure 9).

Rho/ROCK inhibition attenuates lung fibrosis in both bleomycin- and radiation-induced animal models. ${ }^{66,67}$ The molecular mechanisms underlying Rho/ROCK inhibition in the regulation of fibrogenesis are not clear. Y-27632, a highly selective ROCK inhibitor, blocks migration of human neutrophils, macrophages, and fibroblasts in response to chemoattractants in vitro, suggesting that prevention of inflammatory cell infiltration and fibroblast migration into injured lung sites may contribute to the antifibrotic effect of Rho/ROCK inhibition. ${ }^{66,68}$ In addition to regulating fibroblast migration, the Rho/ROCK signal regulates myofibroblast contraction as well.,69 Compared with fibroblasts, fully differentiated myofibroblasts are more hypersynthetic and contractile but less migratory. ${ }^{70,71}$ In this study, we demonstrate that relaxin inhibits IPF lung myofibroblast contraction by inactivation of RhoA/ROCK. In a bleomycin-induced mouse model of lung fibrosis, we administered relaxin into mice at day 14 after bleomycin. At this time, injured murine lungs have passed the acute inflammatory phase (0 to 7 days) and the early fibrotic phase ( 7 to 14 days), during which fibroblast migration occurs, and have entered into the fibrotic phase, during which myofibroblasts are established. This approach limits the inhibitory effect of relaxininduced RhoA/ROCK inactivaction on fibroblast migra-

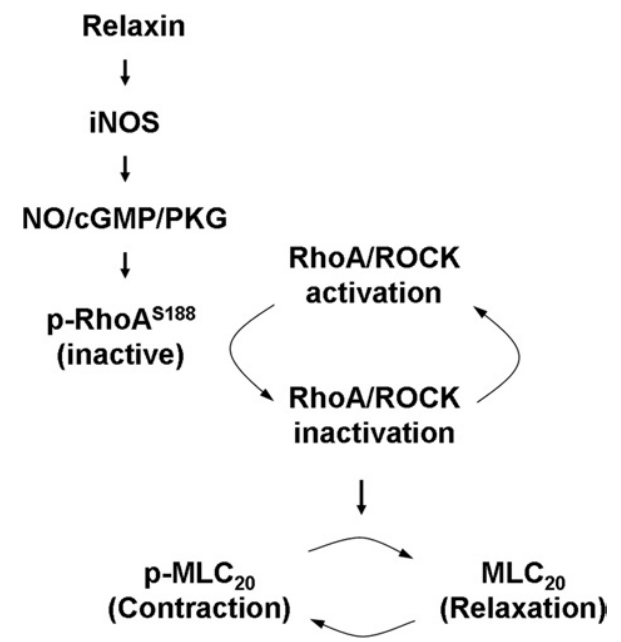

Figure 9. A model for relaxin-mediated cell signaling to inhibit lung myofibroblast contraction. Relaxin promotes iNOS production by lung myofibroblasts, resulting in activation of NO/CGMP/PKG signaling. Elevated PKG activity induces phosphorylation of RhoA at Ser188, which inactivates RhoA and its downstream target, ROCK. Decreased ROCK activity dephosphorylates $\mathrm{MLC}_{20}$ directly and/or through an MLC phosphatase-dependent mechanism, ${ }^{2}$ leading to lung myofibroblast relaxation.

tion while it preserves the effect on myofibroblast contraction. The results show that inhibition of RhoA/ ROCK-induced myofibroblast contraction by relaxin reduced lung fibrosis formation. These data suggest that attenuation of myofibroblast contractility contributes to the antifibrotic effects of Rho/ROCK inhibition.

Myofibroblasts acquire the contractile property similar to SMCs. Both myofibroblast and SMC contractions are determined by phosphorylation (contraction) and dephosphorylation (relaxation) of $\mathrm{MLC}_{2 \mathrm{O}} \cdot{ }^{2,69} \mathrm{Rho} / \mathrm{ROCK}$ signaling phosphorylates myosin phosphatase and inactivates myosin phosphatase activity, which maintains the phosphorylated state of $\mathrm{MLC}_{20}$, resulting in sustained myofibroblast contraction. ${ }^{72-75}$ In this study, we showed that relaxin induces $\mathrm{MLC}_{20}$ dephosphorylation through inhibition of RhoA/ROCK in human lung myofibroblasts, whereas relaxin deficiency results in higher levels of phospho- $\mathrm{MLC}_{20}$ in the lungs of bleomycin-treated mice, compared with levels in WT mice. These data suggest that relaxin is a naturally occurring antagonist of the contractile myofibroblast phenotype in lung fibrosis.

It has been well established that relaxin inhibits myometrial contractility in response to oxytocin and prostaglandin. ${ }^{76}$ CAMP/PKA signaling mediates relaxin-regulated uterine contraction through a mechanism involving the coupling of the relaxin receptor, RXFP1, to multiple G proteins. ${ }^{25,77}$ A previous study ${ }^{56}$ showed that prostacyclin-induced human lung fibroblast and bronchial fibroblast relaxation in three-dimensional collagen matrices occurs through a cAMP/PKA-dependent mechanism, suggesting that the CAMP/PKA signal is involved in the regulation of lung fibroblast contraction. In our studies, neither CAMP levels nor PKA activity is altered by relaxin in IPF (myo)fibroblasts, suggesting that it is unlikely that a cAMP/PKA signal plays a role in relaxin-regulated lung myofibroblast relaxation. Consistent with this, other studies ${ }^{32,78,79}$ have shown that relaxin has little effect on 
CAMP/PKA signal transduction in human uterine fibroblasts, cardiac fibroblasts, and renal myofibroblasts.

Signaling by NO is another important pathway targeted by relaxin. ${ }^{80} \mathrm{NO}$ mediates IL- $1 \beta$-, tumor necrosis factor$\alpha$-, interferon- $\gamma$-, and 3-nitrotyrosine-induced lung fibroblast relaxation in three-dimensional collagen matrices. $^{81-83}$ In addition, a recent study ${ }^{84}$ showed that NO protects the lung from ischemia-reperfusion-induced injury. In the current study, we showed that relaxin promotes NO production, resulting in an increase in the intracellular cGMP level and consequent PKG activation in IPF lung myofibroblasts. Relaxin up-regulation of NO production is iNOS dependent because the expression of iNOS increases in response to relaxin, whereas curcumin, an iNOS-specific inhibitor, blocks relaxin-induced iNOS production. On the other hand, nNOS and eNOS expression levels are not affected by relaxin in the lung. Consistent with these findings, relaxin promotes renal myofibroblast differentiation by increasing NO production $^{40}$; in this study, nNOS, but not iNOS and eNOS, is responsible for relaxin-induced NO production in renal (myo)fibroblasts. These findings suggest that specific NOS isoform(s) are involved in the regulation of NO production by relaxin and may vary depending on the species, organ, and cell types studied. ${ }^{80}$

The small GTPase, RhoA, cycles between an active GTPbound form and an inactive GDP-bound form. The GDP/ GTP cycle controls RhoA activity through three major groups of regulatory proteins: guanine nucleotide exchange factors, GTPase-activating proteins, and guanine dissociation inhibitors. ${ }^{85}$ Recent studies ${ }^{63,86}$ revealed that Rho protein phosphorylation provides an additional means for the regulation of Rho activity that uncouples the classic GDP/GTP cycle. The phosphorylation of RhoA at Ser188 increases the interactions of RhoA with guanine dissociation inhibitors and enhances the ability of guanine dissociation inhibitors to extract RhoA from membranes, leading to RhoA inactivation. ${ }^{62,63}$ In this study, we showed that relaxin-induced NO/cGMP/PKG activation promotes RhoA phosphorylation at Ser188, resulting in RhoA translocation from the plasma membrane to cytosol and disassociation from ROCK that leads to ROCK inactivation. The overexpression of a phosphorylation-resistant RhoA mutant renders IPF lung myofibroblasts refractory to relaxin-induced $\mathrm{MLC}_{20}$ dephosphorylation and relaxation. These results indicate that NO/cGMP/PKG signal-dependent RhoA phosphorylation and ROCK inactivation mediate the inhibitory effect of relaxin on lung myofibroblast contraction.

In this study, we identified a novel antifibrotic mechanism of relaxin involving the inhibition of the contractile phenotype of lung myofibroblasts. Our studies suggest that targeting myofibroblast contraction-induced mechanotransduction may be of therapeutic benefit for the treatment of persistent/progressive fibrotic diseases.

\section{References}

1. Hinz B, Phan SH, Thannickal VJ, Galli A, Bochaton-Piallat ML, Gabbiani G: The myofibroblast: one function, multiple origins. Am J Pathol 2007, 170:1807-1816
2. Tomasek JJ, Gabbiani G, Hinz B, Chaponnier C, Brown RA: Myofibroblasts and mechano-regulation of connective tissue remodelling. Nat Rev Mol Cell Biol 2002, 3:349-363

3. Desmouliere A, Chaponnier C, Gabbiani G: Tissue repair, contraction, and the myofibroblast. Wound Repair Regen 2005, 13:7-12

4. Hinz B: Formation and function of the myofibroblast during tissue repair. J Invest Dermatol 2007, 127:526-537

5. Wipff PJ, Rifkin DB, Meister JJ, Hinz B: Myofibroblast contraction activates latent TGF-beta1 from the extracellular matrix. J Cell Biol 2007, 179:1311-1323

6. Zhou Y, Hagood JS, Lu B, Merryman WD, Murphy-Ullrich JE: Thy-1integrin alphav beta5 interactions inhibit lung fibroblast contractioninduced latent transforming growth factor-beta1 activation and myofibroblast differentiation. J Biol Chem 2010, 285:22382-22393

7. Jaalouk DE, Lammerding J: Mechanotransduction gone awry. Nat Rev Mol Cell Biol 2009, 10:63-73

8. Gunst SJ, Zhang W: Actin cytoskeletal dynamics in smooth muscle: a new paradigm for the regulation of smooth muscle contraction. Am J Physiol Cell Physiol 2008, 295:C576-C587

9. Pollard TD, Borisy GG: Cellular motility driven by assembly and disassembly of actin filaments. Cell 2003, 112:453-465

10. Pak CW, Flynn KC, Bamburg JR: Actin-binding proteins take the reins in growth cones. Nat Rev Neurosci 2008, 9:136-147

11. Ridley AJ, Hall A: The small GTP-binding protein rho regulates the assembly of focal adhesions and actin stress fibers in response to growth factors. Cell 1992, 70:389-399

12. Miralles F, Posern G, Zaromytidou Al, Treisman R: Actin dynamics control SRF activity by regulation of its coactivator MAL. Cell 2003 , 113:329-342

13. Small EM, O'Rourke JR, Moresi V, Sutherland LB, McAnally J, Gerard $\mathrm{RD}$, Richardson JA, Olson EN: Regulation of PI3-kinase/Akt signaling by muscle-enriched microRNA-486. Proc Natl Acad Sci U S A 2010, 107:4218-4223

14. Small EM, Thatcher JE, Sutherland LB, Kinoshita H, Gerard RD, Richardson JA, Dimaio JM, Sadek H, Kuwahara K, Olson EN: Myocardin-related transcription factor-a controls myofibroblast activation and fibrosis in response to myocardial infarction. Circ Res 2010, 107:294-304

15. Morita T, Mayanagi T, Sobue K: Dual roles of myocardin-related transcription factors in epithelial mesenchymal transition via slug induction and actin remodeling. J Cell Biol 2007, 179:1027-1042

16. Masszi A, Speight P, Charbonney E, Lodyga M, Nakano H, Szaszi K, Kapus A: Fate-determining mechanisms in epithelial-myofibroblast transition: major inhibitory role for Smad3. J Cell Biol 2010, 188:383399

17. Zhong C, Chrzanowska-Wodnicka M, Brown J, Shaub A, Belkin AM, Burridge K: Rho-mediated contractility exposes a cryptic site in fibronectin and induces fibronectin matrix assembly. J Cell Biol 1998, 141:539-551

18. Hinz B, Gabbiani G: Cell-matrix and cell-cell contacts of myofibroblasts: role in connective tissue remodeling. Thromb Haemost 2003, 90:993-1002

19. Serini G: Loss of E-cadherin tyrosine phosphorylation in human cancers. Mol Med Today 1999, 5:336

20. Maciver SK: Myosin II function in non-muscle cells. Bioessays 1996 , 18:179-182

21. Barron JT, Barany M, Barany K, Storti RV: Reversible phosphorylation and dephosphorylation of the 20,000-dalton light chain of myosin during the contraction-relaxation-contraction cycle of arterial smooth muscle. J Biol Chem 1980, 255:6238-6244

22. Wu X, Haystead TA, Nakamoto RK, Somlyo AV, Somlyo AP: Acceleration of myosin light chain dephosphorylation and relaxation of smooth muscle by telokin: synergism with cyclic nucleotide-activated kinase. J Biol Chem 1998, 273:11362-11369

23. Pang H, Guo Z, Su W, Xie Z, Eto M, Gong MC: RhoA-Rho kinase pathway mediates thrombin- and U-46619-induced phosphorylation of a myosin phosphatase inhibitor, $\mathrm{CPI}-17$, in vascular smooth muscle cells. Am J Physiol Cell Physiol 2005, 289:C352-C360

24. Pang H, Guo Z, Xie Z, Su W, Gong MC: Divergent kinase signaling mediates agonist-induced phosphorylation of phosphatase inhibitory proteins $\mathrm{PHI}-1$ and $\mathrm{CPI}-17$ in vascular smooth muscle cells. Am J Physiol Cell Physiol 2006, 290:C892-C899 
25. Du XJ, Bathgate RA, Samuel CS, Dart AM, Summers RJ: Cardiovascular effects of relaxin: from basic science to clinical therapy. Nat Rev Cardiol 2010, 7:48-58

26. Bennett RG: Relaxin and its role in the development and treatment of fibrosis. Transl Res 2009, 154:1-6

27. Unemori EN, Pickford LB, Salles AL, Piercy CE, Grove BH, Erikson $\mathrm{ME}$, Amento EP: Relaxin induces an extracellular matrix-degrading phenotype in human lung fibroblasts in vitro and inhibits lung fibrosis in a murine model in vivo. J Clin Invest 1996, 98:2739-2745

28. Kenyon NJ, Ward RW, Last JA: Airway fibrosis in a mouse model of airway inflammation. Toxicol Appl Pharmacol 2003, 186:90-100

29. Bani D, Ballati L, Masini E, Bigazzi M, Sacchi TB: Relaxin counteracts asthma-like reaction induced by inhaled antigen in sensitized guinea pigs. Endocrinology 1997, 138:1909-1915

30. Samuel CS, Zhao C, Bathgate RA, Bond CP, Burton MD, Parry LJ, Summers RJ, Tang ML, Amento EP, Tregear GW: Relaxin deficiency in mice is associated with an age-related progression of pulmonary fibrosis. FASEB J 2003, 17:121-123

31. Samuel CS, Royce SG, Burton MD, Zhao C, Tregear GW, Tang ML: Relaxin plays an important role in the regulation of airway structure and function. Endocrinology 2007, 148:4259-4266

32. Samuel CS, Unemori EN, Mookerjee I, Bathgate RA, Layfield SL, Mak J, Tregear GW, Du XJ: Relaxin modulates cardiac fibroblast proliferation, differentiation, and collagen production and reverses cardiac fibrosis in vivo. Endocrinology 2004, 145:4125-4133

33. Mookerjee I, Unemori EN, Du XJ, Tregear GW, Samuel CS: Relaxin modulates fibroblast function, collagen production, and matrix metalloproteinase-2 expression by cardiac fibroblasts. Ann N Y Acad Sci 2005, 1041:190-193

34. McDonald GA, Sarkar P, Rennke H, Unemori E, Kalluri R, Sukhatme VP: Relaxin increases ubiquitin-dependent degradation of fibronectin in vitro and ameliorates renal fibrosis in vivo. Am J Physiol Renal Physiol 2003, 285:F59-F67

35. Heeg MH, Koziolek MJ, Vasko R, Schaefer L, Sharma K, Muller GA, Strutz F: The antifibrotic effects of relaxin in human renal fibroblasts are mediated in part by inhibition of the Smad2 pathway. Kidney Int 2005, 68:96-109

36. Samuel CS, Mookerjee I, Masterson R, Tregear GW, Hewitson TD: Relaxin regulates collagen overproduction associated with experimental progressive renal fibrosis. Ann N Y Acad Sci 2005, 1041:182184

37. Unemori EN, Amento EP: Relaxin modulates synthesis and secretion of procollagenase and collagen by human dermal fibroblasts. J Bio Chem 1990, 265:10681-10685

38. Unemori EN, Bauer EA, Amento EP: Relaxin alone and in conjunction with interferon-gamma decreases collagen synthesis by cultured human scleroderma fibroblasts. J Invest Dermatol 1992, 99:337-342

39. Williams EJ, Benyon RC, Trim N, Hadwin R, Grove BH, Arthur MJ, Unemori EN, Iredale JP: Relaxin inhibits effective collagen deposition by cultured hepatic stellate cells and decreases rat liver fibrosis in vivo. Gut 2001, 49:577-583

40. Mookerjee I, Hewitson TD, Halls ML, Summers RJ, Mathai ML, Bathgate RA, Tregear GW, Samuel CS: Relaxin inhibits renal myofibroblast differentiation via RXFP1, the nitric oxide pathway, and Smad2. FASEB J 2009, 23:1219-1229

41. Samuel CS, Cendrawan S, Gao XM, Ming Z, Zhao C, Kiriazis H, Xu Q, Tregear GW, Bathgate RA, Du XJ: Relaxin remodels fibrotic healing following myocardial infarction. Lab Invest 2011, 91:675-690

42. Longo M, Jain V, Vedernikov YP, Garfield RE, Saade GR: Effects of recombinant human relaxin on pregnant rat uterine artery and myometrium in vitro. Am J Obstet Gynecol 2003, 188:1468-1474; discussion 1474-1476

43. Norstrom A, Bryman I: Adenosine 3',5'-monophosphate in relation to inhibition of cervical smooth muscle activity in early pregnant women Acta Endocrinol (Copenh) 1991, 125:122-126

44. Baccari MC, Calamai F, Chiappini L, Vannucchi MG, Bani D: Relaxin restores altered ileal spontaneous contractions in dystrophic (mdx) mice. Ann N Y Acad Sci 2005, 1041:308-310

45. Rao MR, Sanborn BM: Relaxin increases calcium efflux from rat myometrial cells in culture. Endocrinology 1986, 119:435-437

46. Bani D, Failli P, Bello MG, Thiemermann C, Bani Sacchi T, Bigazzi M, Masini E: Relaxin activates the L-arginine-nitric oxide pathway in vascular smooth muscle cells in culture. Hypertension 1998, 31: $1240-1247$
47. Masterson R, Hewitson TD, Kelynack K, Martic M, Parry L, Bathgate R, Darby I, Becker G: Relaxin down-regulates renal fibroblast function and promotes matrix remodelling in vitro. Nephrol Dial Transplant 2004, 19:544-552

48. Di Ciano-Oliveira C, Lodyga M, Fan L, Szaszi K, Hosoya H, Rotstein OD, Kapus A: Is myosin light-chain phosphorylation a regulatory signal for the osmotic activation of the $\mathrm{Na}+-\mathrm{K}+-2 \mathrm{Cl}$ - cotransporter? Am J Physiol Cell Physiol 2005, 289:C68-C81

49. Zhou Y, Koli K, Hagood JS, Miao M, Mavalli M, Rifkin DB, MurphyUllrich JE: Latent transforming growth factor-beta-binding protein-4 regulates transforming growth factor-beta1 bioavailability for activation by fibrogenic lung fibroblasts in response to bleomycin. Am J Pathol 2009, 174:21-33

50. Hinz B, Celetta G, Tomasek JJ, Gabbiani G, Chaponnier C: Alphasmooth muscle actin expression upregulates fibroblast contractile activity. Mol Biol Cell 2001, 12:2730-2741

51. Wrobel LK, Fray TR, Molloy JE, Adams JJ, Armitage MP, Sparrow JC Contractility of single human dermal myofibroblasts and fibroblasts. Cell Motil Cytoskeleton 2002, 52:82-90

52. Sawada N, Itoh $H$, Miyashita K, Tsujimoto $H$, Sone M, Yamahara K, Arany ZP, Hofmann F, Nakao K: Cyclic GMP kinase and RhoA Ser188 phosphorylation integrate pro- and antifibrotic signals in blood vessels. Mol Cell Biol 2009, 29:6018-6032

53. Liu G, Friggeri A, Yang Y, Milosevic J, Ding Q, Thannickal VJ, Kaminski N, Abraham E: miR-21 mediates fibrogenic activation of pulmonary fibroblasts and lung fibrosis. J Exp Med 2010, 207:15891597

54. Fumoto K, Uchimura T, Iwasaki T, Ueda K, Hosoya H: Phosphorylation of myosin II regulatory light chain is necessary for migration of HeLa cells but not for localization of myosin II at the leading edge. Biochem J 2003, 370:551-556

55. Iwasaki T, Murata-Hori M, Ishitobi S, Hosoya H: Diphosphorylated MRLC is required for organization of stress fibers in interphase cells and the contractile ring in dividing cells. Cell Struct Funct 2001 26:677-683

56. Kamio K, Liu X, Sugiura H, Togo S, Kobayashi T, Kawasaki S, Wang X, Mao L, Ahn Y, Hogaboam C, Toews ML, Rennard SI: Prostacyclin analogs inhibit fibroblast contraction of collagen gels through the cAMP-PKA pathway. Am J Respir Cell Mol Biol 2007, 37:113-120

57. Togo S, Liu X, Wang X, Sugiura H, Kamio K, Kawasaki S, Kobayashi $\mathrm{T}$, Ertl RF, Ahn Y, Holz O, Magnussen H, Fredriksson K, Skold CM, Rennard SI: PDE4 inhibitors roflumilast and rolipram augment PGE2 inhibition of TGF-\{beta\}1-stimulated fibroblasts. Am J Physiol Lung Cell Mol Physiol 2009, 296:L959-L969

58. Murthy KS, Zhou H, Grider JR, Makhlouf GM: Inhibition of sustained smooth muscle contraction by PKA and PKG preferentially mediated by phosphorylation of RhoA. Am J Physiol Gastrointest Liver Physiol 2003, 284:G1006-G1016

59. Rivero-Vilches FJ, de Frutos S, Saura M, Rodriguez-Puyol D, Rodriguez-Puyol M: Differential relaxing responses to particulate or soluble guanylyl cyclase activation on endothelial cells: a mechanism dependent on PKG-I alpha activation by NO/cGMP. Am J Physiol Cell Physiol 2003, 285:C891-C898

60. Perez-Zoghbi JF, Bai Y, Sanderson MJ: Nitric oxide induces airway smooth muscle cell relaxation by decreasing the frequency of agonist-induced Ca2+ oscillations. J Gen Physiol 2010, 135:247-259

61. Quattrone S, Chiappini L, Scapagnini G, Bigazzi B, Bani D: Relaxin potentiates the expression of inducible nitric oxide synthase by endothelial cells from human umbilical vein in in vitro culture. Mol Hum Reprod 2004, 10:325-330

62. Ellerbroek SM, Wennerberg K, Burridge K: Serine phosphorylation negatively regulates RhoA in vivo. J Biol Chem 2003, 278:1902319031

63. Forget MA, Desrosiers RR, Gingras D, Beliveau R: Phosphorylation states of $\mathrm{Cdc} 42$ and $\mathrm{RhoA}$ regulate their interactions with Rho GDP dissociation inhibitor and their extraction from biological membranes. Biochem J 2002, 361:243-254

64. Sauzeau V, Le Jeune H, Cario-Toumaniantz C, Smolenski A, Lohmann SM, Bertoglio J, Chardin P, Pacaud P, Loirand G: Cyclic GMPdependent protein kinase signaling pathway inhibits RhoA-induced $\mathrm{Ca} 2+$ sensitization of contraction in vascular smooth muscle. J Biol Chem 2000, 275:21722-21729

65. Rolli-Derkinderen M, Sauzeau V, Boyer L, Lemichez E, Baron C Henrion D, Loirand G, Pacaud P: Phosphorylation of serine 188 
protects RhoA from ubiquitin/proteasome-mediated degradation in vascular smooth muscle cells. Circ Res 2005, 96:1152-1160

66. Shimizu Y, Dobashi K, lizuka K, Horie T, Suzuki K, Tukagoshi H, Nakazawa T, Nakazato Y, Mori M: Contribution of small GTPase Rho and its target protein rock in a murine model of lung fibrosis. Am $J$ Respir Crit Care Med 2001, 163:210-217

67. Monceau V, Pasinetti N, Schupp C, Pouzoulet F, Opolon P, Vozenin MC: Modulation of the Rho/ROCK pathway in heart and lung after thorax irradiation reveals targets to improve normal tissue toxicity. Curr Drug Targets 2010, 11:1395-1404

68. Niggli V: Rho-kinase in human neutrophils: a role in signalling for myosin light chain phosphorylation and cell migration. FEBS Lett 1999, 445:69-72

69. Follonier Castella L, Gabbiani G, McCulloch CA, Hinz B: Regulation of myofibroblast activities: calcium pulls some strings behind the scene. Exp Cell Res 2010, 316:2390-2401

70. Ronnov-Jessen L, Petersen OW: A function for filamentous alpha-smooth muscle actin: retardation of motility in fibroblasts. J Cell Biol 1996, 134: $67-80$

71. Hinz B, Dugina V, Ballestrem C, Wehrle-Haller B, Chaponnier C: Alpha-smooth muscle actin is crucial for focal adhesion maturation in myofibroblasts. Mol Biol Cell 2003, 14:2508-2519

72. Tomasek JJ, Vaughan MB, Kropp BP, Gabbiani G, Martin MD, Haaksma CJ, Hinz B: Contraction of myofibroblasts in granulation tissue is dependent on Rho/Rho kinase/myosin light chain phosphatase activity. Wound Repair Regen 2006, 14:313-320

73. Parizi M, Howard EW, Tomasek JJ: Regulation of LPA-promoted myofibroblast contraction: role of Rho, myosin light chain kinase, and myosin light chain phosphatase. Exp Cell Res 2000, 254:210-220

74. Kimura $K$, Ito $M$, Amano $M$, Chihara K, Fukata $Y$, Nakafuku M, Yamamori B, Feng J, Nakano T, Okawa K, Iwamatsu A, Kaibuchi K: Regulation of myosin phosphatase by Rho and Rho-associated kinase (Rho-kinase). Science 1996, 273:245-248

75. Kawano Y, Fukata Y, Oshiro N, Amano M, Nakamura T, Ito M, Matsumura F, Inagaki M, Kaibuchi K: Phosphorylation of myosin-binding subunit (MBS) of myosin phosphatase by Rho-kinase in vivo. J Cell Biol 1999, 147:1023-1038
76. Sherwood OD: Relaxin's physiological roles and other diverse actions. Endocr Rev 2004, 25:205-234

77. Downing SJ, Hollingsworth M: Action of relaxin on uterine contractions: a review. J Reprod Fertil 1993, 99:275-282

78. Palejwala S, Stein D, Wojtczuk A, Weiss G, Goldsmith LT: Demonstration of a relaxin receptor and relaxin-stimulated tyrosine phosphorylation in human lower uterine segment fibroblasts. Endocrinology $1998,139: 1208-1212$

79. Samuel CS, Mookerjee I, Halls ML, Summers RJ, Chew E, Bathgate RA, Tregear GW, Hewitson TD: Investigations into the inhibitory effects of relaxin on renal myofibroblast differentiation. Ann N Y Acad Sci 2009, 1160:294-299

80. Baccari MC, Bani D: Relaxin and nitric oxide signalling. Curr Protein Pept Sci 2008, 9:638-645

81. Zhang HY, Gharaee-Kermani M, Phan SH: Regulation of lung fibroblast alpha-smooth muscle actin expression, contractile phenotype, and apoptosis by IL-1beta. J Immunol 1997, 158:1392-1399

82. Zhu YK, Liu XD, Skold MC, Umino T, Wang H, Romberger DJ, Spurzem JR, Kohyama T, Wen FQ, Rennard SI: Cytokine inhibition of fibroblast-induced gel contraction is mediated by PGE(2) and NO acting through separate parallel pathways. Am J Respir Cell Mol Biol 2001, 25:245-253

83. Sugiura H, Liu X, Ichikawa T, Ichinose M, Rennard SI: 3-Nitrotyrosine inhibits fibroblast-mediated collagen gel contraction and chemotaxis. Eur Respir J 2009, 34:1452-1460

84. Alexiou K, Matschke K, Westphal A, Stangl K, Dschietzig T: Relaxin is a candidate drug for lung preservation: relaxin-induced protection of rat lungs from ischemia-reperfusion injury. J Heart Lung Transplant 2010, 29:454-460

85. Etienne-Manneville S, Hall A: Rho GTPases in cell biology. Nature 2002, 420:629-635

86. Lang P, Gesbert F, Delespine-Carmagnat M, Stancou R, Pouchelet $\mathrm{M}$, Bertoglio J: Protein kinase A phosphorylation of RhoA mediates the morphological and functional effects of cyclic AMP in cytotoxic lymphocytes. EMBO J 1996, 15:510-519 